\title{
Feasibility of Applied Gaming During Interdisciplinary Rehabilitation for Patients With Complex Chronic Pain and Fatigue Complaints: A Mixed-Methods Study
}

Miel A P Vugts ${ }^{1,2}$, MSc.; Margot C W Joosen ${ }^{1}$, PhD; Alfonsus H M M van Bergen ${ }^{2}$, PT; Hubertus J M Vrijhoef ${ }^{1,3}$, Dr, Prof

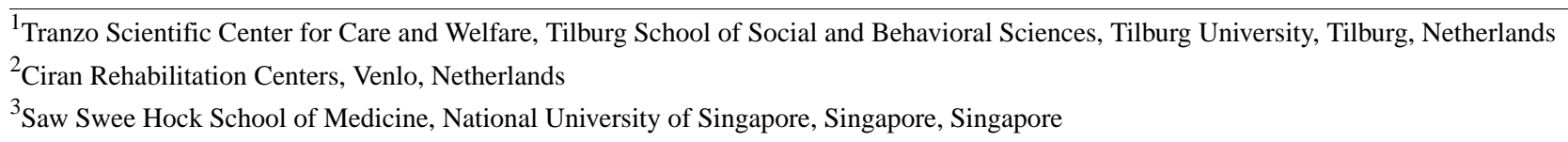

Corresponding Author:

Miel A P Vugts, MSc.

Tranzo Scientific Center for Care and Welfare

Tilburg School of Social and Behavioral Sciences

Tilburg University

P.O. Box 90153

Tilburg, 5000 LE

Netherlands

Phone: 31134668271

Fax: 31134668271

Email: m.a.p.vugts@tilburguniversity.edu

\section{Abstract}

Background: Applied gaming holds potential as a convenient and engaging means for the delivery of behavioral interventions. For developing and evaluating feasible computer-based interventions, policy makers and designers rely on limited knowledge about what causes variation in usage.

Objective: In this study, we looked closely at why and by whom an applied game (LAKA) is demanded and whether it is feasible (with respect to acceptability, demand, practicality, implementation, and efficacy) and devised a complementary intervention during an interdisciplinary rehabilitation program (IRP) for patients with complex chronic pain and fatigue complaints.

Methods: A mixed-methods design was used. Quantitative process analyses and assessments of feasibility were carried out with patients of a Dutch rehabilitation center who received access to LAKA without professional support during a 16-week interdisciplinary outpatient program. The quantitative data included records of routinely collected baseline variables ( $\mathrm{t} 0$ ), additional surveys to measure technology acceptance before ( $\mathrm{t} 1$ ) and after 8 weeks of access to LAKA (t2), and automatic log files of usage behavior (frequency, length, and progress). Subsequently, semistructured interviews were held with purposively selected patients. Interview codes triangulated and illustrated explanations of usage and supplemented quantitative findings on other feasibility domains.

Results: Of the 410 eligible patients who started an IRP during the study period, 116 patients participated in additional data collections (108 with problematic fatigue and 47 with moderate or severe pain). Qualitative data verified that hedonic motivation was the most important factor for behavioral intentions to use LAKA $(P<.001)$. Moreover, quotes illustrated a positive association between usage intentions ( $\mathrm{t} 1)$ and baseline level (t0) coping by active engagement (Spearman $\rho=0.25 ; P=.008)$ and why patients who often respond by seeking social support were represented in a group of 71 patients who accessed the game $(P=.034)$. The median behavioral intention to use LAKA was moderately positive and declined over time. Twenty patients played the game from start to finish. Behavioral change content was recognized and seen as potentially helpful by interview respondents who exposed themselves to the content of LAKA.

Conclusions: Variation in the demand for applied gaming is generally explained by perceived enjoyment and effort and by individual differences in coping resources. An applied game can be offered as a feasible complementary intervention for more patients with complex chronic pain or fatigue complaints by embedding and delivering in alignment with patient experiences. Feasibility, effectiveness, and cost-effectiveness can be evaluated in a full-scale evaluation. New observations elicit areas of further research on the usage of computer-based interventions. 
(JMIR Serious Games 2016;4(1):e2) doi: 10.2196/games.5088

\section{KEYWORDS}

behavioral medicine; therapy; computer-assisted; computer games; mind-body therapies; patient acceptance of health care; feasibility studies; fatigue syndrome, chronic; fibromyalgia; musculoskeletal pain

\section{Introduction}

\section{Background}

Computer-based interventions (CBIs) can be effective alternatives or complements to face-to-face delivery in psychological treatment and chronic illness management [1-4]. However, systematic reviews on effectiveness of CBIs have concluded that sizable and heterogeneous proportions of patients stop using CBIs before completion [5-7]. Nonusage attrition in CBI studies depends on factors such as therapist involvement, demographics, computer self-efficacy, and health status [6-11]. As a strategy to improve patient engagement, some CBI designs have incorporated interactive features [12,13]. Interactive and visual-enriched designs may support patient demand through perceived personal relevance, social support, and enjoyment $[14,15]$. Accordingly, computer game technology has been applied to engage people and to promote health behaviors and clinical outcomes $[16,17]$.

Chronic pain and fatigue complaints constitute a major burden for individuals and societies worldwide [18-20]. Functional somatic syndromes (FSS) are diagnosed by medical specialists when bodily functioning is disturbed, somatic symptoms persist longer than a normal healing process, and conditions cannot be fully attributed to a known conventional disease [21]. A high degree of commonality exists between FSS, wherein central sensitization may be a biological substantiation [22]. FSS can be precipitated by profound life events and cultural factors and maintained by psychosocial factors [20]. Evidence supports the effectiveness of various cognitive and behavioral interventions in primary care settings, or within interdisciplinary rehabilitation programs (IRPs), when "unimodal" psychiatric or physiotherapeutic services do not suffice [20]. Nonetheless, patients were often seen by their general practitioners, but seldom accessed specialized behavioral or multi-modal treatment, and often believed that their complaints are inadequately managed (28\%-62\%) [17].

\section{Literature Review}

Efficient use of scarce resources and removal of access barriers are important motives for developing CBIs [2]. Results on the effectiveness of computer-based behavioral interventions are promising, but uncertainties regarding their actual usage certainly applies to FSS patients [2,23]. Virtual reality and gaming technologies have been applied for triggering positive emotions, distraction, or graded exposure in rehabilitation and pain management for improvements in physical functioning, pain symptoms, and daily life activities [24,25]. However, there has been no evaluation of the effectiveness of applied gaming as an independently accessible means for delivering behavioral change messages to patients with FSS $[16,17,26]$. The actual extent and reasons of patient engagement in applied games will largely determine their effect [16]. A better understanding is needed of why CBIs have not been optimally used by which patients with chronic pain and fatigue symptoms to overcome the treatment barriers they face and why integration of applied gaming can offer a partial solution [2,17-19].

\section{Research Goals}

This study aims to explain the usage of applied gaming and provide a comprehensive feasibility description from the perspective of adult patients with chronic pain and fatigue complaints. The opportunity to conduct this study was provided by the planned incorporation of the applied game "LAKA" within a standardized IRP for adult patients with chronic and complex fatigue or pain symptoms in the Netherlands. The primary objective is to explain variation in the demand for applied gaming when offered for voluntary usage during an IRP. Relationships are studied between usage (intentions), behavioral factors, and patient baseline characteristics, including case mix, functional and clinical status, and medical history. In doing so, this study contributes to a better understanding of why applied games are demanded by patients in real health care settings. Second, feasibility was thoroughly described to prepare for a full-scale evaluation in exploring the domains of acceptability, implementation, practicality, and promise for efficacy. Both research goals are reflected in a conceptual framework (see Multimedia Appendix 1) integrating technology acceptance modeling in a feasibility study design [23-27]. Overall, this contribution enables feasible proposals for incorporating and evaluating an applied game for behavioral change within the rehabilitation of patients with complex chronic pain and fatigue complaints.

\section{Methods}

\section{Research Design}

A mixed-methods design was implemented with sequential quantitative (QN) and qualitative (QL) phases [28] (Figure 1). Owing to the availability of adequate quantitative research instruments, an explanatory sequential mixed-methods design worked well for triangulation, illustration, and complementing QN findings with in-depth QL insights and with practically useful information about feasibility $[29,30]$. The QN phase was prioritized and set up as a longitudinal single-group study of target patient responses to LAKA when offered for voluntary usage during the first 8 weeks of their IRP. The QL phase provided a complementary inductive approach to both research questions. QN and QL phases were mixed in using QN results for the preparation of QL data collection and again when integrating and documenting QN and QL results. 
Figure 1. Mixed-methods design overview.

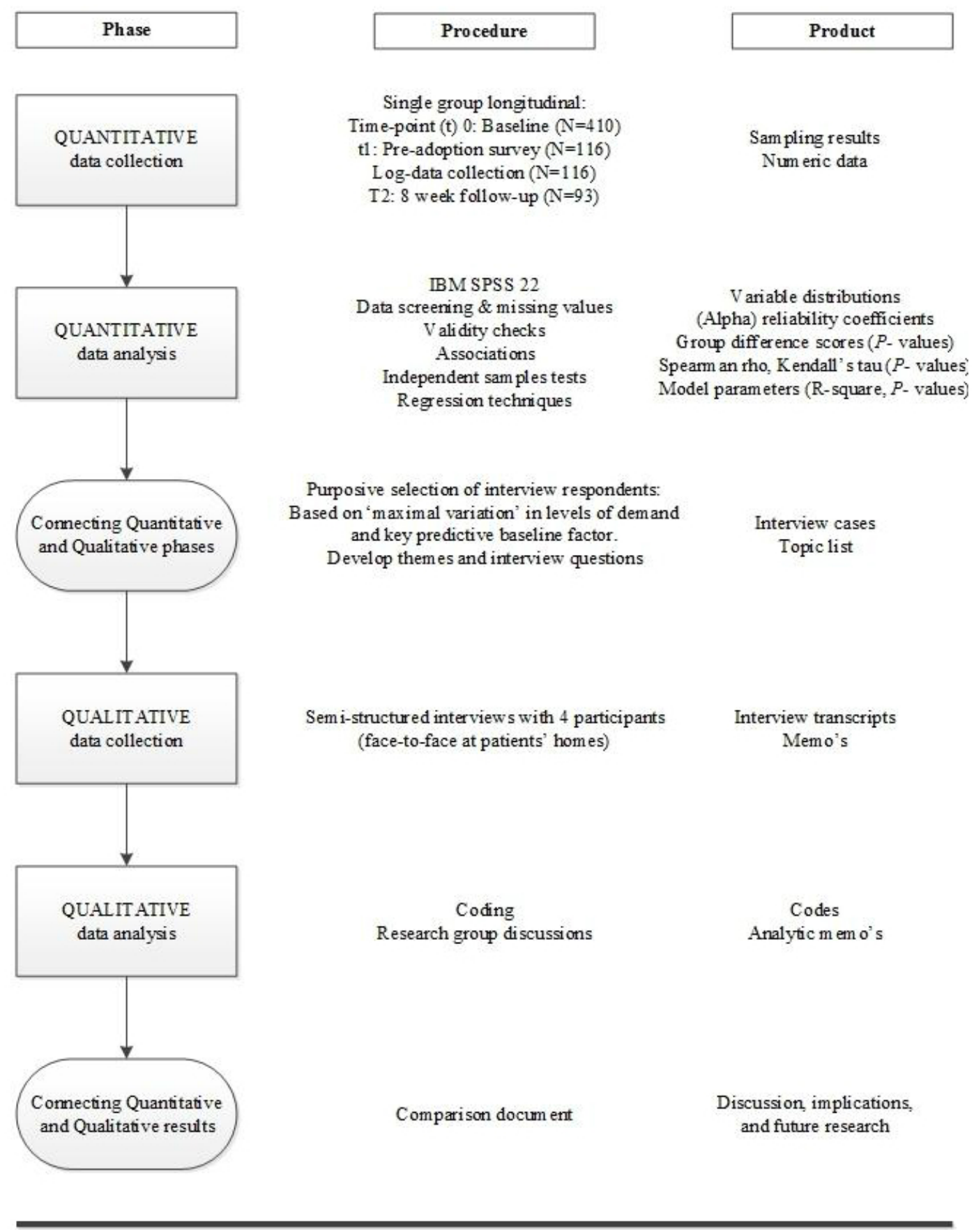

\section{Recruitment and Data Collection}

Ethical approval for the protocol was obtained for this study (at the Psychological Ethical Testing Committee of Tilburg School of Behavioral Sciences, Tilburg University). In total, 410 patients were eligible to start an IRP in 1 of 4 facilities of Ciran, a Dutch rehabilitation center, between 6 January, 2014, and 6 April, 2014 (criteria are listed in Textbox 1) and had given permission to process their diagnostic records for scientific research. Patients in this group were prompted on the day of their first appointment with an email invitation containing information about the nature and consequences of participation in the study, and a link to the "serious gaming page" (see Multimedia Appendix 2). This page guided patients through procedures for software access and additional data collection. Local team leaders were requested to organize face-to-face reminders for patients about the study and the accessibility of LAKA regardless of giving informed consent. 
Textbox 1. Inclusion and exclusion criteria for study participants.

Inclusion criteria:

- Is aged between 18 and 67 years

- Lives in the Netherlands and is proficient in the Dutch language

- Reports the presence of pain for more than 6 months, or fatigue complaints, or a musculoskeletal disease for more than 3 months

- Had received previous primary or secondary health care services without a satisfactory result.

- Reported additional problems on at least 2 of the following problem areas: disturbance of participation, individual or environmental factors, psychological distress, and lack of spiritual well-being

Potential exclusion criteria:

- Presence of medical or psychiatric risk factors (nontreated medical condition, drugs- or alcohol addiction, and suicide risk)

- Presence of third party liabilities

Additional QN data were collected from study participants with two surveys and log-file recordings. The first survey was to be completed within 4 weeks after the invitation and before usage (t1). The second survey (t2) was added to a standard midterm evaluation after 8 IRP weeks, and was to be submitted by the 12th week. Participants' actual usage behavior had been logged automatically between the pre and post surveys. In the intermediate phase, the focus was on "demand" as the primary subject of the study. Two extreme cases were selected so that a relationship between the most predictive baseline characteristic for the use of LAKA could be clearly illustrated. Two more cases were selected with demand levels that were poorly explained by this "key" predictor and more likely to provide information about omitted factors or counterfactuals. QN results were also used to set up an interview schedule. Purposefully selected participants were invited with a prescripted telephone call after their IRP was finished. Interviews were held during 1- to 1.5-hour home visits and were tape-recorded and transcribed. Field notes were taken, and full transcripts were sent to respondents by email within a week after the interview.

\section{Intervention}

A standardized 16-week IRP was delivered by teams of physiotherapists, psychologists, spiritual counselors, and medical rehabilitation specialists (Textbox 2). A full description of the IRP is provided by Garschagen et al [31].

Textbox 2. Characteristics of the interdisciplinary rehabilitation program (IRP).

Tailored: The program has a modular build-up to match individual care need.

Outpatient, intensive: On average, 100 hours delivered by professionals (both individual and group sessions), and 30 self-directed hours.

Integrated program components:

- $\quad 45 \%$ exercise therapy, graded activity, graded exposure, and education in physiology

- $15 \%$ cognitive behavioral therapy

- $15 \%$ counseling and guidance in resuming participation in important life domains, such as work, social activities, and family life

- $25 \%$ spiritual education

Target outcomes:

- $\quad$ Primary: improvement of well-being [32], and participation in important life-domains (activity and participation domains 4-9 of the International Classification of Functioning) [33]

- $\quad$ Secondary: reduce pain, fatigue, and emotional distress symptoms

As recommended, functional requirements were specified before the modeling and evaluation of LAKA [34]. LAKA delivers skills training with metaphorical simulation elements (encounters) and guided exercises for focused attention and open awareness [35]. These elements are interspersed with images of real-world environments, immersive mini-games, and in-game debriefings for "transferring" new insights beyond the virtual world (Textbox 3). Basic information on functional specifications and playability feedback are described and illustrated with screenshots and trailers in Multimedia Appendix
3. A Windows version of LAKA was offered for usage wherever and whenever convenient, without support from health professionals. No recommendation for a minimum or maximum amount of usage was given, and no prompts or reminders were sent. On the one hand, it was expected that many target patients would not use LAKA because of this noncommittal mode of delivery. On the other hand, this variation was desired to discover explanations and practical suggestions that generally apply for delivery in open and clinical settings. 
Textbox 3. LAKA design.

- Problem addressed: In complex cases, suffering associated with FSS has an intrusive impact on patients' existence and their interactions with caregivers, family, or friends [36].

- Design team: The design team involved entrepreneurs, researchers, a scriptwriter, game designers, artists, programmers, audio experts, voice-actors, and IT specialists.

- Stakeholder involvement: Feedback sessions (on functional specifications, theoretical model, and prototypes) involved experts (in behavioral science, medical technology, and spirituality), and critical users.

- Genre: Single-player adventure game.

- Goal (of the game): LAKA was designed to provide skills training in "spiritual" practices. Practices are focused on behavioral qualities that are associated negatively with negative emotions and positively with psychological well-being: "generosity," "moral discipline," "patience/forbearance," "enthusiastic energy," and "mental stability." Accordingly, the design includes the delivery of various behavioral change techniques integrated in an immersive simulation environment.

- Main challenges (in the game): Identify with a personal Avatar and engage in a quest. The story is about an Avatar, who learns about "the art of living" while traveling the world after a significant deterioration of his/her condition. Tasks primarily entail the consideration and evaluation of response options in virtual "encounters" with nonplaying characters.

- Application components: Introduction, 4 training modules (or travel "destinations": London, Turkey, Asia, Africa) with recurrent components, and a celebratory end.

- Duration: Completing the game from start to end takes about 2.5 hours.

- Game controls: Interaction design and controls (with computer mouse and keyboard) were designed for ease of use. Progression in the game does not depend on gamer performance or skill.

- Graphics: Mixed 2D and 3D graphics with comical cut scenes.

- Sound: Voice-overs and music convey emotions and atmosphere.

- Platform: Personal computer or laptop (MS Windows version).

- System requirements: Windows XP or beyond, a 6 gigabytes hard drive, 1 gigabyte memory, and a stable Internet connection.

- Accessibility: Via the "serious gaming" Web page by downloading, or by following instructions for picking up a digital versatile disk at local facilities.

\section{Measures}

\section{Demand, Demand Factors, and Other Feasibility Domain Outcomes}

Objective indicators of demand were based on automatic data logs of participant activities: "frequency" (number of days on which progress was logged), "duration" (sums of time intervals between logins and subsequent data logs), and "progress" (the number of completed encounters). Demand was rated subjectively, before and after usage, by the extent of agreement (1, completely disagree, to 7 , completely agree) with 3 statements about their current behavioral intention (BI) to use LAKA during their IRP $[24,25]$. Seven-point Likert scales were also used to assess behavioral factors, including performance and effort expectancies, social influence, perceived behavioral control, computer anxiety and self-efficacy, hedonic motivation or enjoyment, habit, and trust [23,24,37]. Multimedia Appendix 4 contains details about all survey measures, including variable definitions, items, validity, and reasons why behavioral factors may be relevant [38-46]. Practicality was indicated by counting logins of participants with positive behavioral intentions (BIs at $t 1 \geq 5$ ) as evidence of success in obtaining the software, installation, and running the application. Study and usage attrition were interpreted as indicators of the degree of implementation. Acceptability was operationalized as postusage perceived appropriateness in enjoyment, ease, and knowledge improvement in participants who completed at least the first module of the game.

\section{Baseline Measures}

Retrieved baseline variables were categorized into case mix, functional status, clinical status, and previous treatment variables (see Multimedia Appendix 4). Case-mix variables included sex, age, education level, environmental issues, and treatment facility. Preferred coping styles were measured with the Utrecht Coping List (UCL). Functional status variables included the duration and course of health complaints, employment status, absenteeism, and 1-item general subjective health. Pain intensity was assessed with an 11-point Numerical Rating Scale (NRS) [47]. The Checklist Individual Strength was used to assess fatigue dimensions [48]. Clinical status variables included a categorization of the chronic symptom patterns by a rehabilitation specialist (primarily a fatigue or musculoskeletal or other pain condition). Body mass index (BMI) and blood pressure were measured during physical examination. Psychopathology dimensions were assessed with the Dutch 90-item Symptoms Check List (SCL-90) [49]. The Pain Coping and Cognitions List and Tampa Scale of Kinesiophobia were used to measure pain coping and cognitions [50,51]. Finally, patients indicated previous specialized treatments and current medication intake.

\section{Data Analyses}

\section{Data Exclusion}

Cases were list-wise deleted before analysis if the proportion of missing observations was $<5 \%$, or handled by predicting 5 
data imputations for each empty cell through regression of all variables in the dataset (using the MCMC algorithm). All full-case QN findings presented as marked results are supported by pooled results.

\section{Participant Statistics}

Characteristics of eligible patients, study participants, and participants who logged into the game (players) are described by descriptive statistics and frequencies. Chi square and Mann-Whitney $U$ tests were used to compare baseline level characteristics between study participants and participants who logged into LAKA, versus eligible patients that were not included in those groups. Similarly, differences were tested between participants who logged in versus participants who did not $\log$ in.

\section{Process Analyses of Demand and Feasibility Descriptions}

All feasibility outcomes of applied gaming during the first 8 weeks of the IRP are indicated with descriptive statistics and line graphs. Association measures (Spearman $\rho$ and Kendall $\tau$ statistics) between baseline characteristics, behavioral factors, and feasibility outcomes were calculated and tested for significance. Moreover, multiple ordinary least squares regression analyses were performed for the sequential identification of important constituent factors of behavioral intention at $\mathrm{t} 1$, to explore whether effects of behavioral factors differed between subgroups of patients (see Multimedia Appendix 5), and to test if marked associations between baseline characteristics and behavioral intentions were mediated by behavioral factors [52].

\section{Qualitative Data Analysis}

Interview transcripts were coded by one author (MV) using a software package: MAXQDA 11 (VERBI GmbH) [53]. In the first coding step, all text fragments about the specified interview topics were labeled with short statements that corresponded with contextual meanings. A second author (MJ) independently repeated this first coding step for one interview. These "first order" codes were compared and discussed between MJ and MV to align and refine the coding procedure. In a second coding step, more abstract categories were generated. Throughout this process, first-order codes and emergent categories were constantly compared and hierarchically structured as a means for critical appraisal and to avoid imposing preconceived ideas on the QL data. Finally, categories were related to one another by designating them as context factors, conditions (barriers or facilitators), events or interactions, or consequences.

\section{Mixing Quantitative and Qualitative Results}

In connecting QL and QN findings, codes and statistics were provided for comparison for both research questions. QN results were deemed notable for comparison with QL findings if $P$ values were below .05. Subsequently, 3 researchers (MV, MJ, and $\mathrm{HV}$ ) discussed and determined points of convergence, divergence, or complementariness between QN and QL findings. In doing so, observations were summarized to determine which, and to what extent, remarkable and solid QN findings were clearly illustrated and triangulated. Moreover, the point at which qualitative data collection was stopped was determined on the basis of saturation with respect to illustrations of behavioral factors and the role of a key predictive baseline characteristic for usage in early stages.

\section{Results}

\section{Participant Statistics}

Of the 410 invited eligible patients, $32.2 \%$ provided informed consent and completed the first additional survey (Figure 2). The 84 patients who reported why they did not wish to participate mentioned "other obligations" (23), "facilitative problems" (14), "no intention to use the intervention" (14), "not enough energy or concentration" (13), "no interest to participate in the research" (10), "bodily complaints" (8), or "other reasons" (2). One patient withdrew because of a broken computer, and one for experiencing excessive hindrance in attempting to use an unsupported Web browser. The second questionnaire was submitted by 93 participants $(80.2 \%)$.

Study participants' average age was 44.4 years (SD 10.8 years; range $21-63$ years); $71 \%$ were female (Table 1). Sixty-nine participants were completely absent from work. The average duration of absenteeism was 157 days (SD 223.0), with a median slightly more than 100 days. Forty-seven participants (40.5\%) reported moderate to severe pain (5-10), and 108 experienced problematic fatigue. Average scores for depressive (42.9, SD 11.4) and anxious (22.2, SD 8.2) symptoms were high. Participants had been regularly surfing the Internet, but only 46 patients $(39.7 \%)$ had been playing on a computer over the past year. No statistically significant differences between participants and nonparticipants were found for case-mix variables. However, patients with more severe pain symptoms were underrepresented in the sample (Table 2). The group of 71 patients who actually logged in (players) reported relatively higher scores for coping through active engagement and social support seeking, lower scores for pain coping, and fewer environmental issues. The proportion of patients who had received specialist treatment for their current complaint was lower among players than among nonplayers $\left(\chi_{1}^{2}=4.1 ; P=.042\right.$; not in Table 2).

Four interview respondents were selected based on their combination of scores for coping by active engagement and demand (Table 3). Open questions were asked to introduce and focus on topics (see Multimedia Appendix 6). Two topics addressed the primary research question, namely, "initial response" to the digital game offering (topic 1) and patient "experiences" throughout their interactions with LAKA (topic 2). Topic 2 and "suggestions for improvement" (topic 3), served to collect complementary information on feasibility domains. After a first round of mixing, 4 interviews was deemed sufficient to provide clear illustrations of the most notable QN explanations for demand. 
Table 1. Characteristics of study participants $(\mathrm{N}=116)$.

$\begin{array}{ll}\text { Characteristic }^{\mathrm{a}} & \mathrm{N}(\%)\end{array}$

Demographics

Sex

$$
\text { Female }
$$

Age, years

$\begin{array}{ll}<35 & 23(19.9) \\ 35-45 & 30(25.9) \\ 45-55 & 41(35.3) \\ 55-67 & 22(19.0)\end{array}$

Education level ISCED ${ }^{\mathrm{b}}$

Primary or less

Lower to postsecondary

Tertiary and posttertiary

$40(34.5)$

Missing

\section{Functional status}

Employment in paid work

$\begin{array}{ll}\text { Full-time } & 49(42.2) \\ \text { Part-time } & 52(44.8) \\ \text { None } & 15(12.9)\end{array}$

Absenteeism

$\begin{array}{ll}\text { Not } & 15(26.1) \\ \text { Partially } & 17(14.8) \\ \text { Completely } & 69(59.1)\end{array}$

Duration of absenteeism for present somatic symptoms

$\begin{array}{ll}<3 \text { months } & 31(26.7) \\ 0-3 \text { month } & 41(35.3) \\ 3-6 \text { months } & 22(19.0) \\ 6-12 \text { months } & 14(12.1) \\ 1-2 \text { years } & 6(5.2) \\ >2 \text { years } & 2(1.7)\end{array}$

Symptom duration

$\begin{array}{ll}<3 \text { months } & 3(2.6) \\ 3-6 \text { months } & 11(9.5) \\ 6-12 \text { months } & 30(25.9) \\ 1-2 \text { years } & 27(23.3) \\ >2 \text { years } & 45(38.8)\end{array}$

Pain NRS ${ }^{\mathrm{b}}$

$\begin{array}{ll}\text { No pain (0) } & 18(15.5) \\ \text { Mild pain (1-4) } & 51(44.0) \\ \text { Moderate pain (5-7) } & 36(31.0) \\ \text { Severe pain (7-10) } & 11(9.5)\end{array}$


$\begin{array}{ll}\text { Characteristic }^{\mathrm{a}} & \mathrm{N}(\%)\end{array}$

No fatigue $\left(\mathrm{NRS}^{\mathrm{b}}=0\right)$

$2(1.7)$

Not problematic $\left(\right.$ CIS $\left.^{\mathrm{b}} \leq 76\right)$

Problematic (CIS > 76)

$108(94.7)$

CIS subjective fatigue ${ }^{\mathrm{c}}$

Above average

CIS physical activity

Below average

$67(58.8)$

\section{Clinical status}

Primary diagnosis

Chronic musculoskeletal disorder

Chronic pain

Chronic fatigue

SCL- $90^{\mathrm{b}}$ depression $^{\mathrm{d}}$

Below average (16-31)

Above average (32-35)

7 (6.0)

High (36-52)

$63(54.3)$

Very high $(\geq 53)$

SCL-90 anxiety ${ }^{\mathrm{d}}$

Below average (10-17)

42 (36.2)

Above average (18)

7 (6.0)

High (19-28)

39 (33.6)

Very high $(\geq 29)$

\section{Previous treatment}

Medical specialist treatment

Medication usage

\section{Previous use of similar technology}

Habit of frequent Internet usage with a PC or laptop

On 6-7 days per week

On 3-5 days per week

On 1-2 days per week

On $<1$ day per week

Experience of digital game play

$$
\begin{aligned}
& \text { Never played a digital game } \\
& \text { More than a year ago } \\
& \text { Less than a year ago } \\
& \text { Less than a month ago }
\end{aligned}
$$




\begin{tabular}{lll}
\hline Characteristic $^{\mathrm{a}}$ & $\mathrm{N}(\%)$ & \\
\hline & One or more times per month (and less than a month ago) & $29(25)$ \\
\hline
\end{tabular}

${ }^{\mathrm{a}} \mathrm{A}$ selection of individual baseline characteristics is presented to facilitate comparison with previous evaluations of behavioral interventions for FSS patients $[54,55]$.

${ }^{\mathrm{b}}$ CIS: Checklist Individual Strength, ISCED: International Standard Classification of Education (according to which highest education levels [Dutch system] were rescaled [low $=0-1$, middle $=2-4$, high $=5-6]$ [ [56], NRS: Numerical Rating Scale, SCL: Symptom Checklist.

${ }^{\mathrm{c}}$ For all participants ( 2 missing values were ignored; $\mathrm{N}=114$ ). In comparison with the average in a population of patients with chronic fatigue syndrome [57].

${ }^{\mathrm{d}}$ Compared with a population of Dutch patients with chronic pain [49]. 
Table 2. Overview of independent samples tests.

\begin{tabular}{lll}
\hline Variable & $\begin{array}{l}\text { Participants (N=116) } \\
\text { vs nonparticipants }^{\mathrm{a}}\end{array}$ & $\begin{array}{l}\text { Players (N=71) } \\
\text { vs nonplayers or nonparticipants }^{\mathrm{a}}\end{array}$ \\
\hline & $\begin{array}{l}\text { Mean (SD)/frequency (\%), } \\
\text { Mean (SD)/frequency (\%), }\end{array}$ \\
$P$ value of test statistic $^{\mathrm{b}}$ & $P$ value of test statistic $^{\mathrm{b}}$
\end{tabular}

\section{Case mix}

Female (dit.) $^{\mathrm{b}}$

Age $^{\mathrm{b}}$

Education level

$\mathrm{UCL}^{\mathrm{c}}$ active engagement

UCL passive responding

UCL social support seeking

UCL comforting thought

Environmental issue (dit.)

Location A (dit.)

Location B (dit.)

Location C (dit.)

Location D (dit.)

\section{Clinical status and functioning}

Body mass index

Indication for chronic fatigue (dit.)

Indication for musculoskeletal disorder (dit.)

Indication for chronic pain (dit.)

Symptom duration

Symptom recurrence (dit.)

Symptom deterioration (dit.)

Paid work (dit.)

$\mathrm{SCL}^{-} 90^{\mathrm{c}}$ total

SCL-90 sleeping problems

SCL-90 hostility

SCL-90 interpersonal sensitivity

SCL-90 insufficiency

SCL-90 somatization

SCL-90 depression

SCL-90 anxiety

SCL-90 agoraphobia

Pain NRS ${ }^{\mathrm{c}}$

$\mathrm{PCCL}^{\mathrm{c}}$ internalization

PCCL pain coping

PCCL catastrophizing

$\mathrm{TSK}^{\mathrm{c}}$

$$
\begin{aligned}
& 71(61.2), .48 \\
& 44.4(10.8), .91 \\
& 3.3(1.3), .12 \\
& 17.6(4.0), .53 \\
& 14.3(3.7), .29 \\
& 13.9(4.0), .06 \\
& 12.0(2.7), .74 \\
& 61(53.4), .07 \\
& 39(33.6), .39 \\
& 27(23.3), .41 \\
& 29(25.0), .53 \\
& 21(18.1), .45
\end{aligned}
$$

$27.1(5.8), .32$

78 (67.2), .045

21 (18.1), .16

17 (14.7), .37

Median $>2$ years, .75

$74(63.8) .75$

69 (59.5), .04

101 (87.1), .12

206.9 (50.7), .70

9.1 (3.3), .18

11.3 (4.5), .38

34.9 (12.7), .58

$26.0(7.0), .73$

30.7 (8.3), .86

42.9(11.4), .69

$22.2(8.2), .86$

$11.0(5.4), .60$

$\mathrm{N}=47^{\mathrm{d}}$

6.5 (1.3), .046

$3.2(.7), .09$

$2.8(.8), .06$

$3.6(.8), .04$

$36.7(6.8), .80$
45 (63.4), .92

44.1 (11.3), .88

3.3 (1.3), .40

18.5 (3.9), .02

14.0 (4.0), .11

14.1 (4.0), .03

12.4 (2.7), .38

34 (47.9), .02

18 (25.4), .30

19 (26.8), .89

18 (25.4), .59

16 (22.5), .64

$27.4(5,5), .17$

54 (76.1), .002

9 (12.7),.03

8 (11.3), .14

Median >2 years, .34

44 (62.0), .68

43 (60.6), .20

62 (87.3), .23

206.3 (51.2), .94

9.0 (3.4), .23

11.1 (4.1), .69

33.9 (12.4), .63

26.6 (6.9), .27

31.3 (7.7), .40

41.8 (11.7), .55

22.4 (8.5), .99

$11.5(6.0), .73$

$\mathrm{N}=27^{\mathrm{d}}$

$6.6(1.4), .21$

$3.3(.7), .18$

$2.7(.8), .009$

$3.6(.8), .11$

$36.4(7.1), .64$ 


\begin{tabular}{|c|c|c|}
\hline & Participants $(\mathrm{N}=116)$ & Players $(\mathrm{N}=71)$ \\
\hline Variable & vs nonparticipants $^{\mathrm{a}}$ & vs nonplayers or nonparticipants ${ }^{\mathrm{a}}$ \\
\hline & $\mathrm{N}=108^{\mathrm{e}}$ & $\mathrm{N}=69^{\mathrm{e}}$ \\
\hline $\mathrm{CIS}^{\mathrm{c}}$ subjective fatigue & $50.5(6.0), .32$ & $50.4(5.6), .85$ \\
\hline CIS concentration & $26.3(8.1), .59$ & $26.0(8.4), .57$ \\
\hline CIS motivation & $21.3(6.1), .59$ & $21.4(6.1), .63$ \\
\hline CIS physical (in)activity & $17.2(4.0), .83$ & $16.9(4.1), .30$ \\
\hline \multirow[t]{2}{*}{ CIS total score } & $110.1(14.8), .99$ & $109.4(14.1), .64$ \\
\hline & $\mathrm{N}=101^{\mathrm{f}}$ & $N=62^{f}$ \\
\hline Part-time work (dit.) & $52(53.1), .72$ & $33(46.5), .57$ \\
\hline Weekly work hours & $31.6(11.9), .21$ & $29.8(15.4), .12$ \\
\hline Absent (dit.) & $86(74.1), .94$ & $54(87.1), .60$ \\
\hline UBOS-a ${ }^{c}$ burnout (dit.) & $26(22.4), .33$ & $16(22.5), .48$ \\
\hline UBOS mental exhaustion & $3.9(1.5), .72$ & $4.0(1.5), .47$ \\
\hline UBOS distancing & $2.3(1.5), .81$ & $2.4(1.6), .99$ \\
\hline \multirow[t]{2}{*}{ UBOS work competence } & $4.0(1.2), .20$ & $4.1(1.1), .08$ \\
\hline & $\mathrm{N}=86^{\mathrm{g}}$ & $\mathrm{N}=54^{\mathrm{g}}$ \\
\hline Partially absent (dit.) & 17 (14.7), . 31 & $13(24.1), .94$ \\
\hline Sick leave duration & 159.8 (223.4), .91 & $150.4(15.4), .36$ \\
\hline \multicolumn{3}{|l|}{ Previous treatment } \\
\hline Medication intake (dit.) & 70 (60.3), .48 & $39(58.2), .06$ \\
\hline Previous specialist treatment (dit.) & $81(69.8), .50$ & $47(66.2), .83$ \\
\hline
\end{tabular}

${ }^{\mathrm{a}}$ These comparisons were chosen to inform about study sample profiles and how successful the implementation was in recruiting representative subsamples for exploring "within-group" variation in demand. The players versus nonplayers comparison did not yield more remarkable differences.

${ }^{\mathrm{b}} \mathrm{N}(\%)$ and $P$ value of chi-square if variable is dichotomous (dit.); median (N) or mean (SD) and $P$ value of Mann-Whitney $U$ test if variable is an ordinal or a ratio scale value.

${ }^{\mathrm{c}}$ CIS: Checklist Individual Strength, PCCL: Pain Coping and Cognitions, SCL: Symptom Checklist, TSK: Tampa Scale of Kinesiophobia, UBOS-a: Utrecht Burnout Scale labor (a) version, UCL: Utrecht Coping List.

${ }^{d}$ Subsample of participants with moderate or severe pain, ${ }^{e}$ with problematic fatigue, and ${ }^{\mathrm{f}}$ with paid work and of those ${ }^{\mathrm{g}}$ absent from work. 
Table 3. Characteristics of interview respondents.

\begin{tabular}{lllll}
\hline Characteristic & Respondent \#1 ${ }^{\mathrm{a}}$ & Respondent \#2 & Respondent \#3 & Respondent \#4 \\
\hline Usage (session days, encounters) & 3,20 & 0,0 & 1,1 & 2,4 \\
Behavioral intention & 6 & 1 & 4 & 7 \\
UCL active engagement ${ }^{\mathrm{a}}$ & Very high & Very low & Very high & Average \\
Sex & Male & Male & Female & Female \\
Age, years & 35 & 57 & 62 & 54 \\
Work status & No paid work & Fully absent for 97 days & Fully absent for 287 days & Present at work \\
CIS fatigue severity & Problematic & Above-average CFS ${ }^{\text {b }}$ & Above-average CFS & Problematic \\
Pain NRS & 3 & 1 & 3 & 0 \\
SCL $^{\mathrm{d}}$ anxiety & Average & $<$ Average & High & High \\
\hline
\end{tabular}

${ }^{\mathrm{a}}$ Cases were identified by inspection of a bivariate scatterplot displaying the most predictive individual baseline characteristic on the $\mathrm{x}$-axis; frequency of usage on the y-axis; and marking dots representing negative (<3), neutral (3-5), and positive ( $>5)$ behavioral intentions at $\mathrm{t}$.

${ }^{b}$ Levels of active engagement within the sample are similar to healthy worker population levels. Norm scores are slightly different for males and females. ${ }^{\mathrm{c}}$ As compared to average fatigue severity in a sample of patients diagnosed with chronic fatigue syndrome.

${ }^{\mathrm{d} C I S}$ : Checklist Individual Strength, NRS: Numerical Rating Scale, SCL: Symptom Checklist, UCL: Utrecht Coping List.

Figure 2. Flow diagram of study participants.

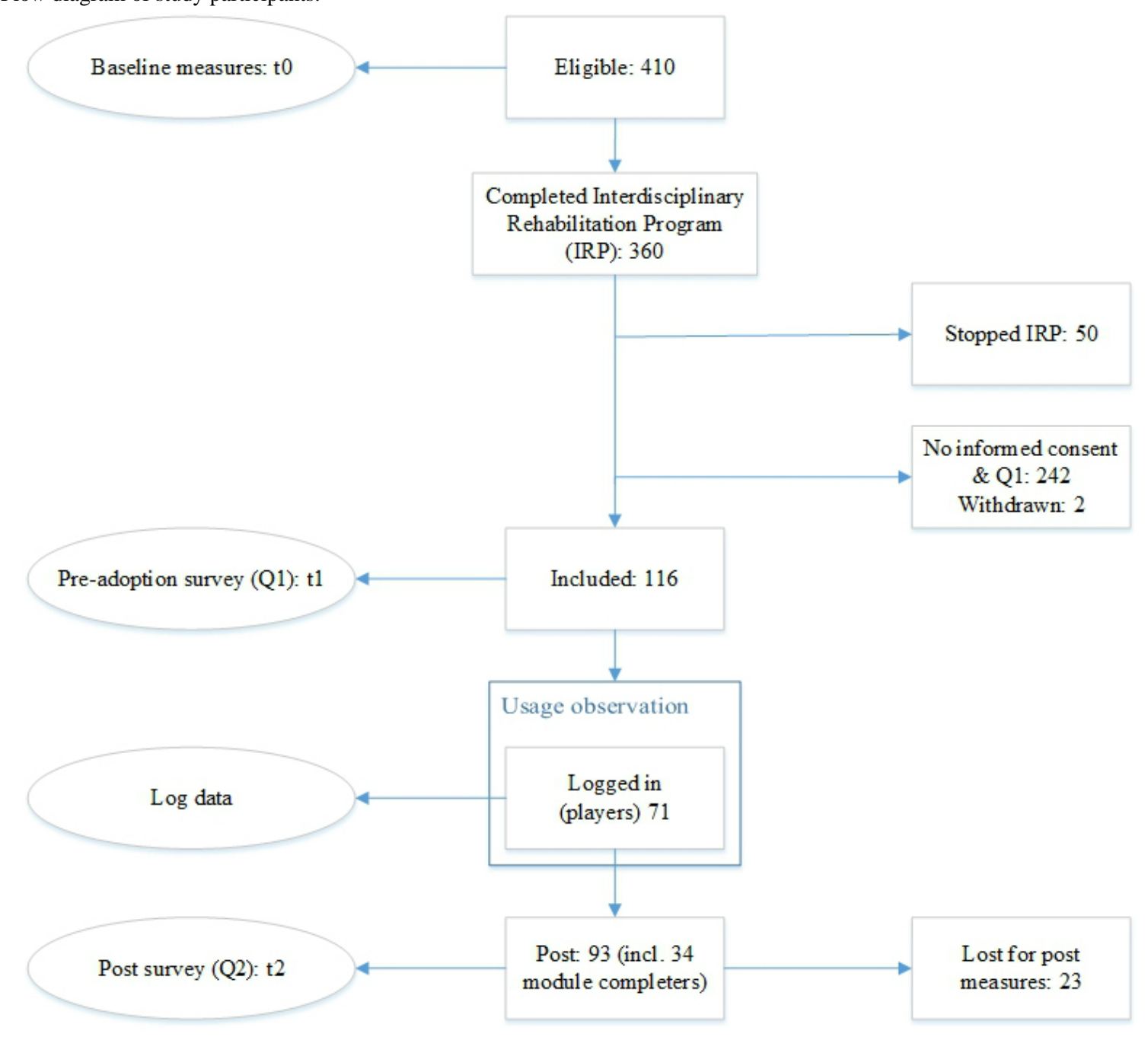




\section{Process of Demand}

\section{Direct effects}

Actual usage indicators measured at preadoption were associated with behavioral intention at a moderate level at $\mathrm{t} 1(\rho=.527-.546)$, and weakly at t2 $(\rho=.260-.273)$. Behavioral intention was associated with various behavioral factors measured at $\mathrm{t} 1$ (Table 4 ). Effects of perceptions on performance, social norms, and knowledge improvement became stronger over time and with exposure to LAKA. Expectancies of effort and performance independently shared a significant amount of variance with behavioral intention at $\mathrm{t} 1$ (Table 5). Second step models were superior to the core model if supplemented with hedonic motivation or habit, but not if other factors were added. Inclusion of hedonic motivation weakened the effects of core factors such that performance expectancy was no longer a significant factor for behavioral intention.

If asked openly for an explanation of their own initial response to the offer to play LAKA during their IRP, respondents first explained their affect or attitude at that time, such as their openness to try the intervention. These feelings were substantiated by memories of previous experiences with computer game play. Those who felt positive about using the game did not experience barriers in concerns about privacy, usefulness, opinions of others, or a lack of resources. Nonetheless, respondents desired an explanation about how the intervention could bring about personal benefit.
I do like games. I have them myself... I'm just going to see what it is. Not immediately: no, I do not join in... I was just open minded... With two or three people I have talked about it (eds.: study, LAKA), and they said: the only thing for which I look at the computer, is to see what time I should be here. For other things; let me know... [Respondent \#4]

I did not recognize a goal... If there was a little more explanation, then I would have probably played ... and especially if it helps. [Respondent \#2]

Various associations between case-mix variables and demand indicators were marked (Table 6). Frequency of coping by active engagement and comforting thought were positively related to demand before exposure. Associations between demand indicators and social support seeking increased by exposure. BI was significantly lower for participants treated in location A, whereas participants treated in location D progressed more within the game. BI measured after 8 weeks was associated negatively with education level and positively with age. Notable differences in demand by functional and clinical status variables were also observed. LAKA was played more frequently by participants who reported partial absenteeism from work and lower pain coping scores. Higher usage was registered for players with higher levels of perceived competence in their job, symptom deterioration, higher pain intensity, lower internalization, and fewer symptoms of anxiety at baseline.

Table 4. Associations between demand indicators and behavioral factors.

\begin{tabular}{|c|c|c|c|}
\hline Behavioral factor & $\begin{array}{l}\mathrm{BF} \mathrm{t} 1 \text { with } \mathrm{BI} \mathrm{t} 1^{\mathrm{a}} \\
\mathrm{N}=115^{\mathrm{b}} \\
\left(\rho \text { or } \tau, P^{c}\right)\end{array}$ & $\begin{array}{l}\text { BF t1 with BI t2 } \\
\mathrm{N}=92 \\
(\rho \text { or } \tau, P)\end{array}$ & $\begin{array}{l}\text { BF t2 with BI t2 } \\
\mathrm{N}=32 \\
(\rho, P)\end{array}$ \\
\hline Performance expectancy & $.33,<.001$ & $.19, .08$ & $.59,<.001$ \\
\hline Expected ease & $.42,<.001$ & $.10, .37$ & $.35, .045$ \\
\hline Social influence & $0.14, .13$ & $.17, .11$ & $.42, .01$ \\
\hline Perceived behavioral control & $.33,<.001$ & $.04, .71$ & $.22, .22$ \\
\hline Trust & $.31, .001$ & $.21, .049$ & $.53, .001$ \\
\hline Hedonic motivation & $.54,<.001$ & $.43,<.001$ & $.61,<.001$ \\
\hline Computer anxiety & $-.27, .003$ & $.10, .35$ & \\
\hline Computer self-efficacy & $.22, .02$ & $.32, .002$ & \\
\hline Habit (dichotomous) & $.22^{\mathrm{c}}, .007$ & $.06^{\mathrm{c}}, .53$ & \\
\hline Perceived knowledge improvement & & & $.77,<.001$ \\
\hline
\end{tabular}

${ }^{\mathrm{a}} \mathrm{BI}$ : behavioral intention, BF: behavioral factor, t: time-point.

${ }^{\mathrm{b}}$ Pairwise deletion: one respondent submitted an unfinished web-survey at $\mathrm{t} 1$.

${ }^{\mathrm{c}}$ Kendall $\tau$ (for dichotomous variable) or Spearman $\rho$ (for other variables), $P$ value. 
Table 5. Parameters and models fit of multiple regression for constituent factors of behavioral intention at preadoption.

\begin{tabular}{|c|c|c|c|c|}
\hline $\begin{array}{l}\text { Parameters } \\
\left(\mathrm{N}=115^{\mathrm{a}}\right)\end{array}$ & $\begin{array}{l}\text { Model } 1: \\
\text { Core TAM } \\
\text { beta }(P \text { value })\end{array}$ & $\begin{array}{l}\text { Model } 2: \\
\text { UTAUT }^{\text {b }} \\
\text { beta }(P \text { value })\end{array}$ & $\begin{array}{l}\text { Model 3: } \\
\text { Core+HM }{ }^{\mathrm{b}} \\
\text { beta }(P \text { value })\end{array}$ & $\begin{array}{l}\text { Model } 4: \\
\text { Core+HB } \\
\text { beta }(P \text { value })\end{array}$ \\
\hline Constant & $.84(.15)$ & $.34(.63)$ & $.89(.10)$ & $.69(.23)$ \\
\hline$P E^{c}$ & $.40(.002)$ & .35 (.009) & $.04(.79)$ & $.46(<.001)$ \\
\hline $\mathrm{EE}^{\mathrm{c}}$ & $.52(<.001)$ & $.51(<.001)$ & $.27(.02)$ & $.47(.001)$ \\
\hline $\mathrm{SI}^{\mathrm{c}}$ & & $.15(.09)$ & & \\
\hline $\mathrm{PBC}^{\mathrm{c}}$ & & $.06(.63)$ & & \\
\hline $\mathrm{HM}^{\mathrm{c}}$ & & & $.59(<.001)$ & \\
\hline \multirow[t]{2}{*}{$\mathrm{HB}^{\mathrm{c}}$} & & & & $.63(.02)$ \\
\hline & $\mathrm{R}^{2}\left(P \text { of } \Delta \mathrm{R}^{2}\right)^{\mathrm{c}}$ & $\mathrm{R}^{2}\left(P \text { of } \Delta \mathrm{R}^{2}\right)^{\mathrm{d}}$ & $\mathrm{R}^{2}\left(P \text { of } \Delta \mathrm{R}^{2}\right)^{\mathrm{d}}$ & $\mathrm{R}^{2}\left(P \text { of } \Delta \mathrm{R}^{2}\right)^{\mathrm{d}}$ \\
\hline Model & $.34(<.001)$ & $.36(.22)$ & $.43(<.001)$ & $.38(.02)$ \\
\hline
\end{tabular}

${ }^{\mathrm{a}}$ Observations of 1 incomplete case were listwise deleted.

${ }^{b}$ EE: effort expectancy, HB: habit, HM: hedonic motivation, TAM: technology acceptance model, UTAUT: unified theory of acceptance and use of technology, PBC: perceived behavioral control, PE: performance expectancy, SI: social influence.

${ }^{\mathrm{c}, \mathrm{d}} P$ of $\Delta \mathrm{R}^{2}$ is the $P$ value of variance explained by the model over ${ }^{\mathrm{c}}$ a constant-only model, or ${ }^{\mathrm{d}}$ over model 1 . 
Table 6. Associations between baseline characteristics and demand indicators.

\begin{tabular}{|c|c|c|c|c|c|c|}
\hline Baseline variable & $\begin{array}{l}\text { BI t } 1 \\
\rho \text { or } \tau, P^{\mathrm{a}}\end{array}$ & $\begin{array}{l}\text { Session days } \\
\rho \text { or } \tau, P\end{array}$ & $\begin{array}{l}\text { Session days } \\
\rho \text { or } \tau, P\end{array}$ & $\begin{array}{l}\text { Time spent } \\
\rho \text { or } \tau, P\end{array}$ & $\begin{array}{l}\text { Progress } \\
\rho \text { or } \tau, P\end{array}$ & $\begin{array}{l}\text { BI t2 } \\
\rho \text { or } \tau, P\end{array}$ \\
\hline \multicolumn{7}{|l|}{ Case-mix } \\
\hline & $\mathrm{N}=116$ & $\mathrm{~N}=116$ & $\mathrm{~N}=71$ & $\mathrm{~N}=71$ & $\mathrm{~N}=71$ & $\mathrm{~N}=93$ \\
\hline Female (dit) ${ }^{\mathrm{a}}$ & $-.04, .59$ & $-.03, .77$ & $-.10, .34$ & $-.10, .29$ & $-.13, .22$ & $-.08, .38$ \\
\hline Age & $-.10, .28$ & $-.02, .84$ & $-.05, .69$ & $.03, .78$ & $-.00, .97$ & $.25, .02$ \\
\hline Education level (ISCED) ${ }^{\mathrm{b}}$ & $-.05, .60$ & $-.12, .18$ & $-.21, .08$ & $-.24, .048$ & $-.24, .048$ & $.28, .006$ \\
\hline $\mathrm{UCL}^{\mathrm{b}}$ active engagement & $.25, .008$ & $.30, .001$ & $.23, .06$ & $.13, .29$ & $.13, .28$ & $.11, .31$ \\
\hline UCL passive responding & $-.09, .32$ & $-.16, .08$ & $-.19, .12$ & $.02, .86$ & $-.02, .89$ & $.02, .82$ \\
\hline UCL social support seeking & $.09, .37$ & $.19, .045$ & $.23, .052$ & $.20, .08$ & $.24, .04$ & $.08, .43$ \\
\hline UCL comforting thought & $.20, .03$ & $.19, .04$ & $.11, .36$ & $.09, .44$ & $.09, .48$ & $.05, .62$ \\
\hline Environmental issue (dit.) & $-.15, .06$ & $-.03, .13$ & $.13, .22$ & $.07, .48$ & $.10, .34$ & $.06, .50$ \\
\hline Location A (dit.) & $-.17, .03$ & $-.22, .01$ & $-.13, .22$ & $-.18, .06$ & $-.19, .07$ & $-.02, .86$ \\
\hline Location B (dit.) & $.07, .42$ & $.01, .93$ & $-.15, .15$ & $-.14, .17$ & $-.18, .08$ & $-.091, .31$ \\
\hline Location C (dit.) & $.07, .37$ & $.06, .47$ & $.15, .18$ & $.12, .23$ & $.14, .18$ & $.030, .74$ \\
\hline Location D (dit.) & $.06, .46$ & $.19, .03$ & $.15, .17$ & $.21, .03$ & $.24, .02$ & $.084, .35$ \\
\hline
\end{tabular}

\section{Clinical and functional status}

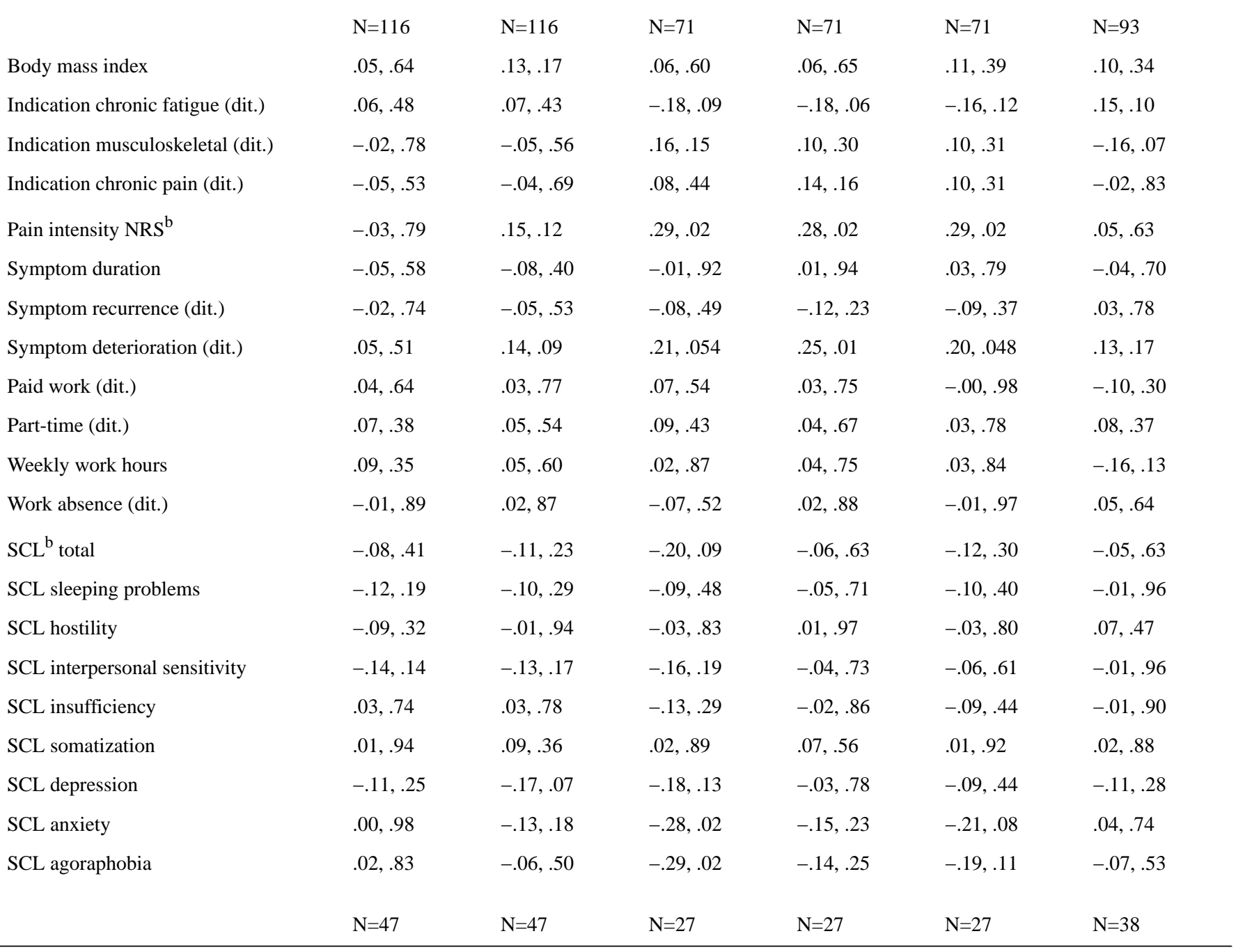




\begin{tabular}{|c|c|c|c|c|c|c|}
\hline Baseline variable & $\begin{array}{l}\text { BI t1 } \\
\rho \text { or } \tau, P^{\mathrm{a}}\end{array}$ & $\begin{array}{l}\text { Session days } \\
\rho \text { or } \tau, P\end{array}$ & $\begin{array}{l}\text { Session days } \\
\rho \text { or } \tau, P\end{array}$ & $\begin{array}{l}\text { Time spent } \\
\rho \text { or } \tau, P\end{array}$ & $\begin{array}{l}\text { Progress } \\
\rho \text { or } \tau, P\end{array}$ & $\begin{array}{l}\text { BI t } 2 \\
\rho \text { or } \tau, P\end{array}$ \\
\hline PCCL internalization & $.14, .37$ & $-.11, .46$ & $-.36, .07$ & $-.42, .03$ & $-.48, .01$ & $-.06, .73$ \\
\hline PCCL pain coping & $-.03, .87$ & $-.35, .02$ & $-.28, .16$ & $-.25, .21$ & $-.26, .19$ & $-.01, .95$ \\
\hline PCCL catastrophizing & $.03, .83$ & $.02, .92$ & $.16, .42$ & $.30, .14$ & $.25, .21$ & $.03, .84$ \\
\hline \multirow[t]{2}{*}{ TSK kinesiophobia } & $-.08, .61$ & $-.08, .58$ & $.09, .67$ & $.26, .20$ & $.23, .25$ & $-.08, .64$ \\
\hline & $\mathrm{N}=108$ & $\mathrm{~N}=108$ & $\mathrm{~N}=69$ & $\mathrm{~N}=69$ & $\mathrm{~N}=69$ & $\mathrm{~N}=86$ \\
\hline $\mathrm{CIS}^{\mathrm{b}}$ subjective fatigue & $-.04, .66$ & $-.09, .38$ & $-.07, .55$ & $-.02, .90$ & $-.10, .42$ & $.03, .80$ \\
\hline CIS concentration & $.07, .49$ & $-.10, .30$ & $-.15, .22$ & $-.05, .67$ & $-.09, .47$ & $.15, .16$ \\
\hline CIS motivation & $-.08, .44$ & $-.05, .59$ & $-.13, .29$ & $-.04, .72$ & $-.10, .41$ & $.19, .08$ \\
\hline CIS physical or inactivity & $.02, .81$ & $-.05, .60$ & $.02, .90$ & $.13, .27$ & $.09, .48$ & $-.04, .75$ \\
\hline \multirow[t]{2}{*}{ CIS total score } & $-.02, .82$ & $-.12, .22$ & $-.18, .14$ & $-.06, .64$ & $-.13, .29$ & $.16, .15$ \\
\hline & $\mathrm{N}=101$ & $\mathrm{~N}=101$ & $\mathrm{~N}=62$ & $\mathrm{~N}=62$ & $\mathrm{~N}=62$ & $\mathrm{~N}=93$ \\
\hline UBOS-a burnout (dit.) & $-.01, .95$ & $-.10, .30$ & $-.23, .050$ & $-.17, .10$ & $-.20, .06$ & $.04,67$ \\
\hline UBOS-a mental exhaustion & $.03, .77$ & $.01, .90$ & $-.08, .55$ & $-.11, .42$ & $-.11, .38$ & $.11, .35$ \\
\hline UBOS-a distancing & $.10, .93$ & $-.08, .40$ & $-.19, .15$ & $-.16, .22$ & $-.20, .12$ & $.10, .36$ \\
\hline \multirow[t]{2}{*}{ UBOS-a work competence } & $.15, .14$ & $.19, .052$ & $.29, .02$ & $.27, .03$ & $.32, .01$ & $-.14, .22$ \\
\hline & $\mathrm{N}=86$ & $\mathrm{~N}=86$ & $\mathrm{~N}=54$ & $\mathrm{~N}=54$ & $\mathrm{~N}=54$ & $\mathrm{~N}=69$ \\
\hline Partially vs. fully absent (dit.) & $.06, .55$ & $.26, .01$ & $.27, .03$ & $.18, .11$ & $.20, .09$ & $.09, .40$ \\
\hline Sick leave duration & $.21, .054$ & $.13, .24$ & $.02, .91$ & $.01, .96$ & $.00, .98$ & $-.10, .41$ \\
\hline \multicolumn{7}{|l|}{ Previous treatment } \\
\hline & $\mathrm{N}=116$ & $\mathrm{~N}=116$ & $\mathrm{~N}=71$ & $\mathrm{~N}=71$ & $\mathrm{~N}=71$ & $\mathrm{~N}=93$ \\
\hline Medication intake (dit.) & $-.09, .44$ & $-.15, .09$ & $-.13, .22$ & $-.10, .31$ & $-.11, .27$ & $.02, .79$ \\
\hline Specialist treatment (dit.) & $-.03, .72$ & $-.06, .53$ & $.16, .16$ & $.08, .41$ & $.15, .15$ & $.09, .35$ \\
\hline
\end{tabular}

${ }^{a} \rho$ : Spearman $\rho$ statistic was calculated when both variables had interval or ratio measurement levels, $\tau$ : Kendall $\tau$ statistic was calculated for dichotomous level independent variables (dit.) $P: P$ value of test statistic.

${ }^{\mathrm{b}}$ CIS: Checklist Individual Strength, ISCED: International Standard Classification of Education Level, NRS: Numerical Rating Scale, PCCL: Pain Coping and Cognitions, SCL: Symptom Checklist, TSK: Tampa Scale of Kinesiophobia, UBOS-a: Utrecht Burnout Scale labor (a) version, UCL: Utrecht Coping List.

Three interview respondents who exposed themselves to LAKA explained their level of engagement by witnessing that game tasks were welcome challenges in early stages of a rehabilitation process. However, patient users' attention shifted away from gaming tasks toward the pace (slow) and structure of the game when their confidence and engagement in "real-life" roles increased (eg, noticing that selecting preprogrammed alternatives is not as complex as responding in real life, and purposively selecting "bad" responses to explore the "rules" that guide scenarios). Disengagement was also explained by the belief of being incapable to perform a certain task.

At the time of the program... I was on sick leave. What could I do? I really had time for the computer, and no energy for anything else... When I stopped, it was enough for me. The game is too slow for me... For my energy that I've built up again... I started working again. I'm going to a sports club. Yes, my life, my rhythm, is different... I have no time. [Respondent \#3] In work, I am constantly adjusting to people. So for me it did not really matter... I have an ADHD problem. So, attention exercises are a disaster for me. I have no patience for that... The first time I went on to see where I got stuck when I was just giving 'wrong' answers... Occasionally, when you had to wait, I was like: come on, hurry. [Respondent \#1]

\section{Moderation and Mediation Effects}

Performance expectancy was a significantly stronger predictor of behavioral intention at $\mathrm{t} 1$ in patients primarily diagnosed with chronic fatigue rather than a chronic pain condition (beta=.98; $P<.001$ ), and high levels of depressive symptoms (beta=.91; $P=.006$ ). The relationship between social influence 
and behavioral intention was affected negatively by the more than 6-month absenteeism (beta= .61; $P=.01$ ). Daily Internet usage over the past year strengthened the positive effect of hedonic motivation on behavioral intention at preadoption (beta=.63; $P=.001$ ). The negative association between computer anxiety and behavioral intention was significantly weaker in participants younger than 45 years (beta $=.42 ; P=.009$ ). Mediation analyses showed that perceived behavioral control mediated the effect of active engagement on behavioral intention at preadoption, but did not mediate the effect of active engagement on the presence of a log-in.

Focusing on individual differences in coping with the delivery of LAKA during interviews yielded self-descriptions by patients, which varied between being "curious, a gamer, and capable" to play versus being neither a "games person" nor an "early adopter" and believing that computer games are difficult to play.

Anyway, I am someone who games a lot ... Did not doubt about being able to play it. I am someone who wants to follow and keep up with things ... There are buttons, and all the buttons I want to have tried them at least once. [Respondent \#1]

Most games that happen to PCs, such as Tetris and things like that... That is under time pressure ... No, that does not attract me and I cannot do that ... I'm not the pioneer to go on my own. [Respondent \#2]

\section{Feasibility Description}

\section{Demand}

At the preadoption stage, most participants had a moderately positive intention to use LAKA over the next 4 months in addition to their scheduled IRP activities (Table 7). Nine participants $(7.8 \%)$ with low initial behavioral intention ( 2 or lower) were statistical outliers, but were not excluded from further analyses. BI decreased over the course of 8 weeks. On average, players completed 8 encounters, which equals 2 of 4 modules in total. The first module of the game was completed by 40 patients $(56.3 \%)$. Twenty players $(28.2 \%)$ completed the game from start to end. A line graph (Figure 3) shows that players were more likely to stop using the game when they headed for a new game, module, or element.

\section{Implementation and Practicality}

Of 85 participants, $59(69.4 \%)$ with a positive intention to use $(B I \geq 5)$ logged in successfully. At treatment facility A, 12 of the 24 willing participants logged in $(50 \%)$, which is significantly less $\left(\chi_{1}^{2}=5.9 ; P=.015\right)$ than the proportions of participants at the other 3 locations (70.6\%-81.0\%). Players who possessed more computer platforms (ie, a tablet, a console, a mobile phone) progressed less within the game $(\rho=.39$; $P=.001)$. Most activity was recorded during the first 4 weeks of participants' IRPs (Figure 4). When playing at home, participants logged in at different times during the day, but mostly after 6 pm (Figure 5).

Table 7. Descriptive results of demand level assessment.

\begin{tabular}{|c|c|c|c|c|c|c|}
\hline Demand indicator & $\mathrm{N}$ & Mean & Median & $\mathrm{SD}^{\mathrm{a}}$ & Min & $\operatorname{Max}$ \\
\hline $\mathrm{BI}^{\mathrm{a}}$ at $\mathrm{t} 1$ & 116 & 5.1 & 5 & 1.4 & 1 & 7 \\
\hline $\mathrm{BI}$ at $\mathrm{t} 2$ & 93 & 3.5 & 4 & 2.0 & 1 & 7 \\
\hline Session days & 71 & 1.8 & 2 & 1.4 & 0 & 6 \\
\hline Time spend & 71 & $1: 14: 40$ & $0: 52: 25$ & $1: 07: 42$ & 0:00:00 & $4: 22: 27$ \\
\hline Progression & 71 & 8.1 & 7 & 7.3 & 0 & 32 \\
\hline
\end{tabular}

${ }^{\mathrm{a}} \mathrm{BI}$ : behavioral intention, SD: standard deviation. 
Figure 3. The proportions of players who stopped using LAKA at certain stages of progress.

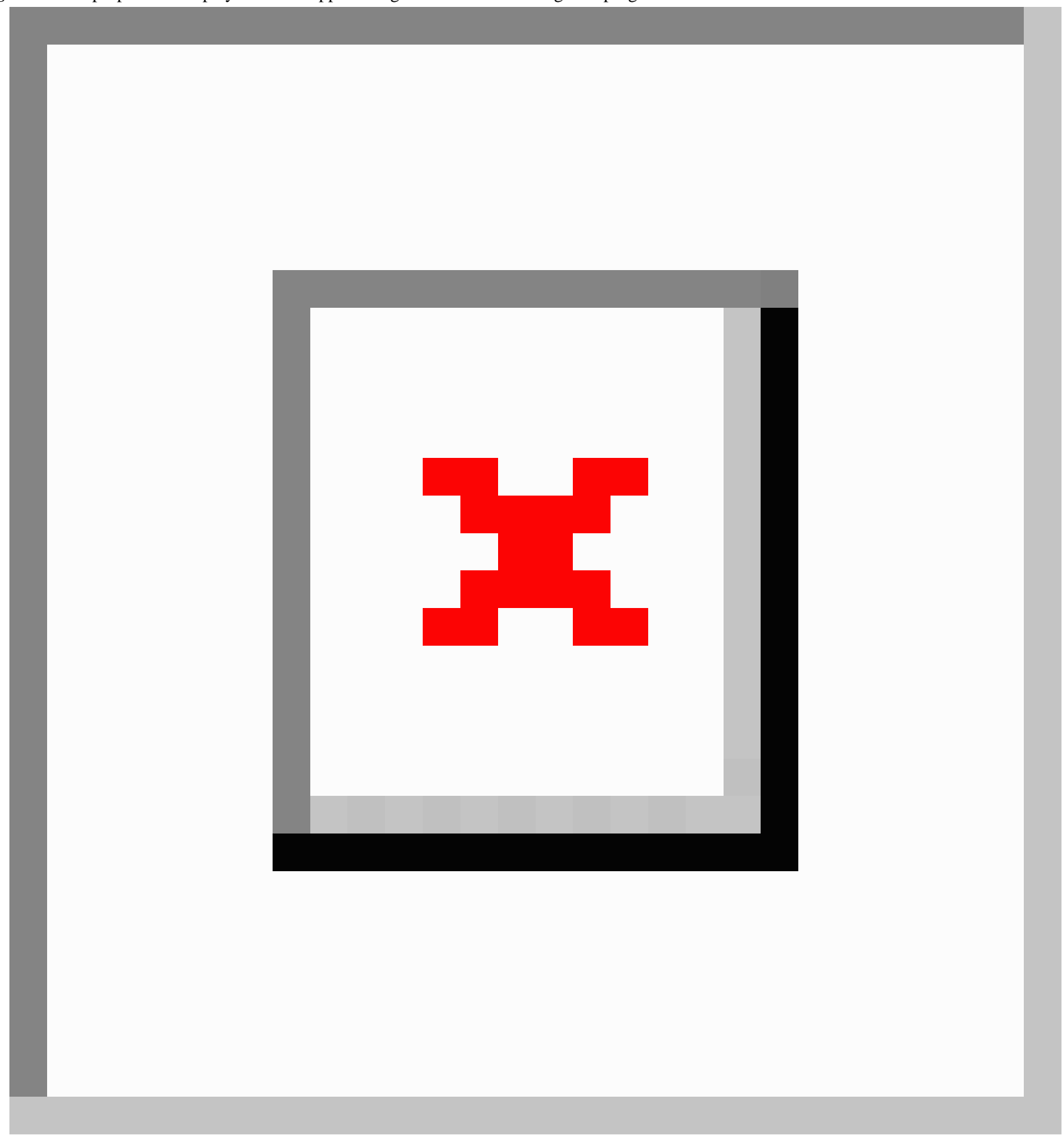


Figure 4. Sums of logged in game activities throughout the first 12 weeks of patients' IRPs.

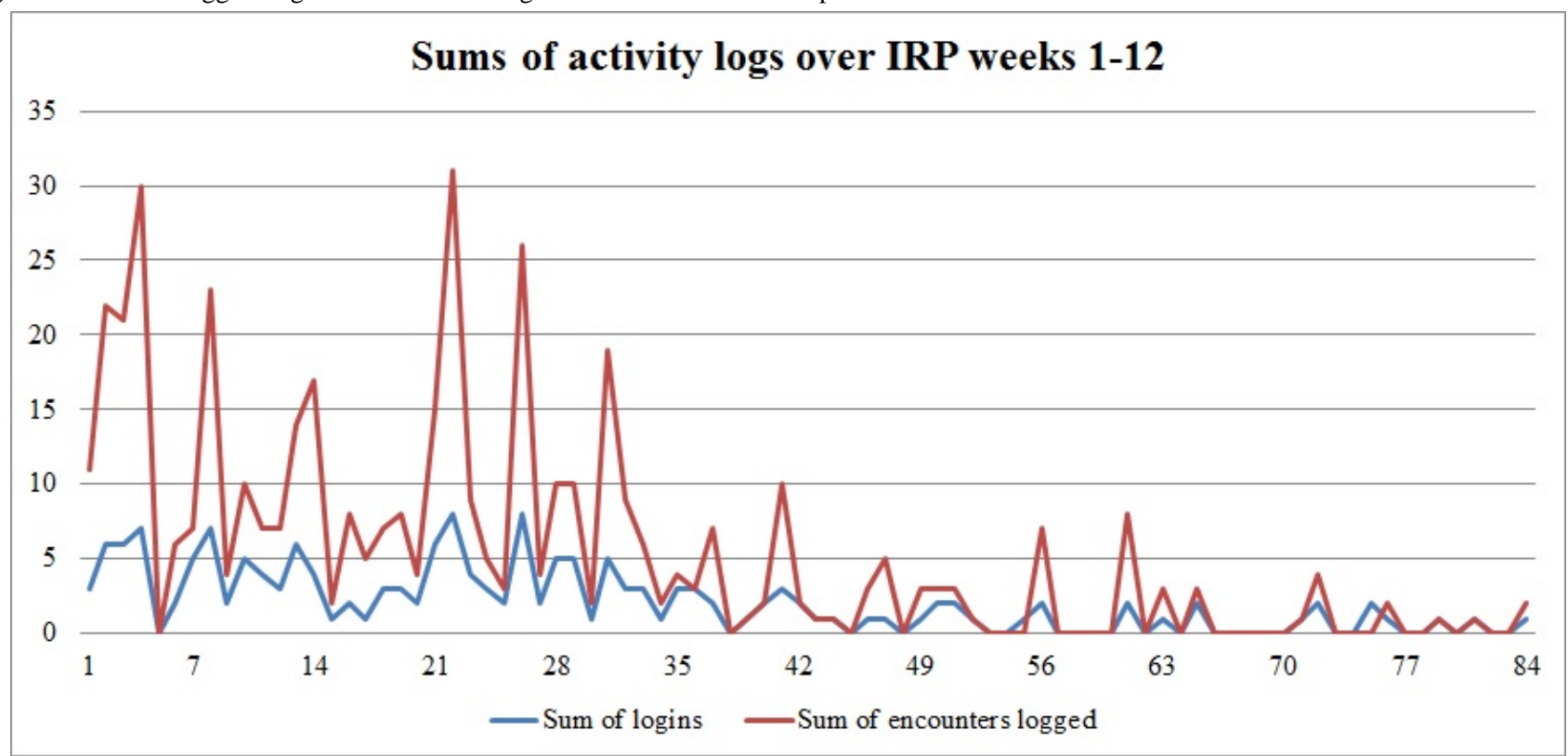

Figure 5. Number of logins by participants by time of the day.

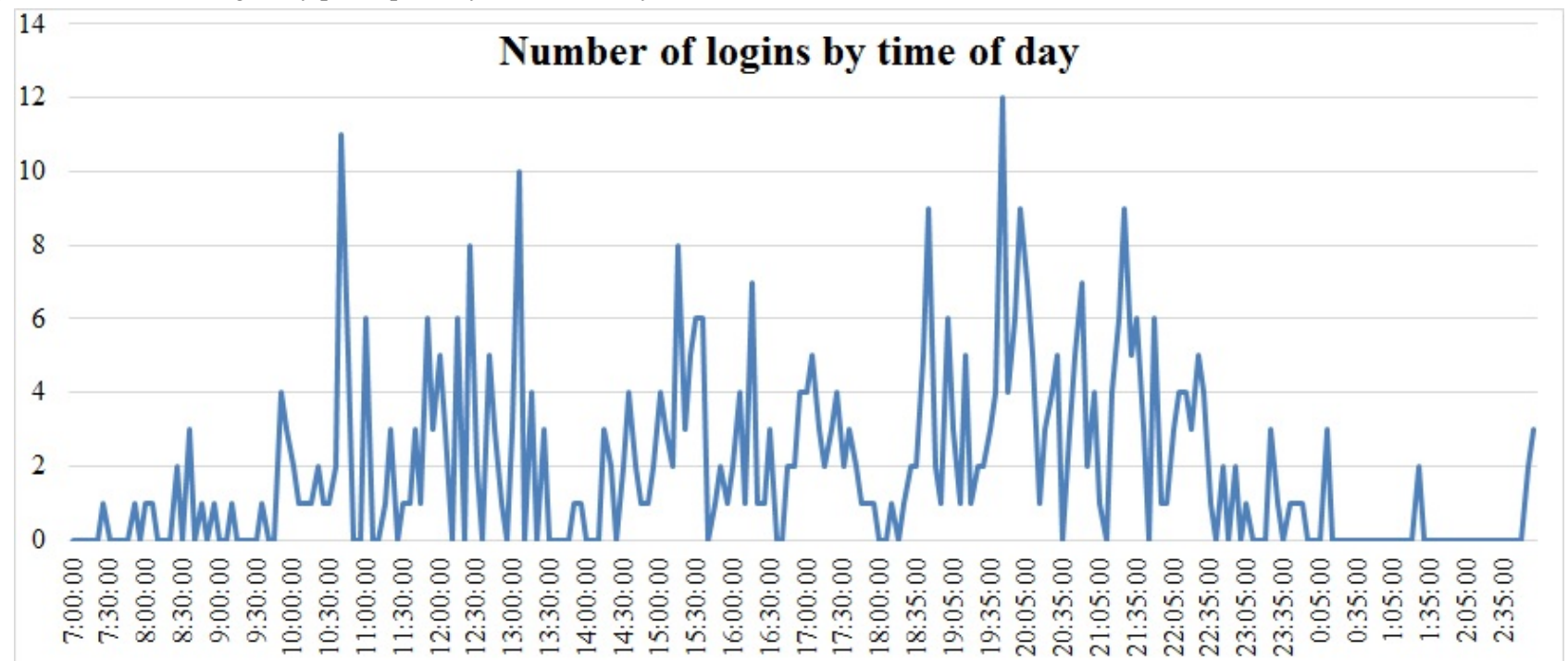

\section{Acceptability and Potential for Efficacy}

Postusage perceived ease, rated by those who played the first module of LAKA, was moderately high (mean 5.4/7 (SD 1.54); median 6/7) and varied positively with baseline active engagement $(\rho=.45 ; P=.007)$, motivation $(\rho=.57 ; P=.001)$, and indication of a chronic musculoskeletal disorder $(P=.008)$. Perceived enjoyment levels were moderately positive (mean 4.6 (SD 1.7)), and positively associated with baseline concentration problems $(\rho=.44 ; P=.01)$. Postusage perceived knowledge improvement (mean 4.6/7 (SD 1.8)) was lower in participants with a higher BMI $(\rho=.42 ; P=.02)$.

Interview respondents who played LAKA (respondents 1, 3, and 4) believed that it was a suitable program component. A variety of game elements were appointed that were liked. Furthermore, tasks were quickly understood, taken seriously, and experienced as a fit with the approach taken in other program components. "Encounters" were recognized as representations of real-life situations. Respondents who played generally believed that they could select options that corresponded with their intentions. Experienced consequences were acquaintance with meditation, concentration, and reflections on ideal and "healthy" selves, rumination, and adequate ways of responding.

I saw pretty quickly where they wanted to go with it. In that respect, it does well with what they do at Ciran. [Respondent \#1]

I have a computer, then it is no problem... I could use that game well... Later you find out: oh, it's not just a game. It is something to think about your own situation... Then you're not in the game, but you are in reality... All kinds of possibilities were offered 
(referring to response options in encounters): what I see as negative, in between, and what I see as 'good'... It was also a bit about ... as I was during the illness... I could recognize myself in some situations: Yes, that was the old <patient name>... At the moment however, I react completely differently. I could see that. Maybe that also influenced me: my healing. [Respondent \#3]

During the game you were forced to concentrate; not wanting to go through it too fast... Actually you were just forced to use your concentration... It occurs to me that I ruminate long about something, and it also confronts you with that... Those first meditation exercises... I really needed to do it a few times ... That got me meditating... [Respondent \#4]

\section{Suggestions for Improvement}

Respondents suggested to integrate LAKA, similar to other program elements patients normally adhere to. Additional support was desired by means of a personalized introduction early in the program, information about how to get something out of the game and about what is achieved afterward, professional feedback on situations in the game, and facilities for gaming at Ciran locations. Suggestions for playability were to match the pace of in-game interaction with skill or health status and to extend software support to multiple platforms.

I would certainly continue to offer it. Maybe someone should be designated to introduce it at an early stage... To show it, and to show what you can get out of it for yourself. In a playful way ... If an entire manual should be read, then you put it away quickly... Actually, I do most with the IPad. If that is possible... I rarely use a pc. [Respondent \#4]

I would let everyone play. I think if it is offered in $<$ location name>... "If there is a psychologist... that is better. Immediately talk about those reactions taking place at that time... find out faster what kind of situations played a role in becoming so ill, and get better.. Maybe you could combine it ... a bit slower in the beginning and a little faster at the end. [Respondent \#3]

\section{Discussion}

\section{Principal Findings}

This study primarily questioned why and by which patients with chronic pain and fatigue complaints is applied gaming for behavior change demanded during an IRP. Voluntary applied gaming (LAKA) was generally explained over time by perceived enjoyment and ease. Coping resources are important to solve delivery issues, get in control, and start using an applied game. Patient environment, health status, and performance expectancies were relevant factors for the usage of an applied game in conjunction with time and exposure.

Second, feasibility was described in preparation for a full-scale evaluation. A substantial number of patients played the game under noncommittal conditions. According to them, LAKA will be acceptable and useful. Active ingredients were recognized and deemed to be relevant in early stages of a rehabilitation process. Patients suggested delivering the game with social support through early and expeditious communication about how and when the game is relevant for their rehabilitation and with extended technical facilities.

\section{Strengths and Limitations}

This study provides the first empirical results on a novel applied game for behavioral change in patients with chronic pain and fatigue complaints. Comprehensive information is presented on processes of self-selection, acceptance, and attrition, which provides rare insights into risk factors for bias in CBI evaluations [58]. Mixed methodology strategy worked well to triangulate QN findings with newly collected QL data. Important demand explanations are based on notable and robust statistical results supported by a decent sample size and clear illustrations with QL data. QN results that were not clearly illustrated with QL data, or were based on more selective patient samples, provided practical information and clues for future research. More than a final feasibility assessment, this study contributed with general and utilizable knowledge for the future deployment of applied gaming for FSS patients in practice.

Limitations should be considered when drawing general conclusions about the feasibility of applied gaming for FSS patients. Feasibility was not assessed against a control group level or a reasonable benchmark. Technology acceptance measures are commonly used, but they are often contextually adapted and serve in theory building rather than feasibility assessment. Furthermore, this study builds on pragmatic eligibility criteria and convenience sampling of Dutch patients. It cannot be ruled out that early judgments about the nature of the delivery mode affected results via self-selection. Performing a large number of explorative statistical tests threatens statistical power and internal validity. Caution should be exercised when interpreting causality in relationships between behavioral factors and behavioral intentions because independent and dependent variables were measured at the same point in time, and hedonic motivation was not clearly distinct from performance expectancies and behavioral intentions. Whether the use of technology acceptance questionnaires alone would be an appropriate method for assessing the usage of gaming technology, especially at a time when patients may have difficulty processing information, can be doubted and is not recommended. Finally, advanced statistical techniques such as partial least squares regression [59] or newer process analyses techniques [60] would have been appropriate, but were not used. QN method limitations were addressed by triangulation of key QN findings with QL data, comprehensive sample description, validity checks, residual analysis, and sensitivity analyses (for outlier removal, measures of association, and regression method; see Multimedia Appendix 7).

\section{Comparison With Prior Work}

Researchers have stressed that a better understanding of the demand for CBIs is a major concern in overcoming barriers to treatment of patients with chronic pain and fatigue symptoms $[2,3]$. To our knowledge, this is the first empirical study on applied gaming for the delivery of behavioral intervention for patients with chronic somatic symptoms and functional 
problems. Findings suggest that voluntary engagement in applied gaming is strongly driven by positive affect. The importance of hedonic motivation for demand is remarkable because this is an often-omitted factor in previous research on the use of information technology in health care [27]. Concerns about utility, demonstrability of results, privacy, or consultation seemed to have a limited effect on demand in this case, when patients had no previous experiences. Ubiquitous interview quotes about "openness" hinted that inclinations to search for meaning or personal growth could partially explain demand for applied gaming $[61,62]$. Concluding that FSS patients will use an applied game "for the sake of the activity itself" is tentative. Applied gaming interventions are relatively new and barely institutionalized, and limited information was available to patients about the efficacy of LAKA or a similar game. It could also be that patients thought about usefulness and trustworthiness of care before deciding on following an IRP. Moreover, findings on influences of individual differences in coping styles and perceptions of control and ease on the usage of LAKA correspond with those of earlier studies that found a positive effect of internal locus of control on the adherence to a web-based positive psychology intervention [9]. Such results might also reflect differences in executive functioning or capacities for self-control [63].

Other remarkable QN results, which were not clearly illustrated with QL data, are discussed in connection with past research or as areas of future research. Findings on the effect of depressed mood on CBI usage have been heterogeneous [30]. This study pointed in the direction of a negative relationship, but found no statistically significant direct effect. This might be because of the comparatively high levels of psychopathologic symptoms of these FSS patients [64]. A moderation effect is indicated by extremely low BIs that were found exclusively in patients with low to neutral performance expectancies and high levels of depressive symptoms. Furthermore, computer anxiety and experience might explain differences in relationships between age and technology usage found in earlier studies [27]. Moreover, patients with lower scores for pain intensity and those who indicated fatigue as their primary complaint were more likely to self-select as a player, whereas patients with higher pain intensity played more once exposed. Further research on the usage of CBIs could focus on understanding "matches" between symptom characteristics, "readiness," and demanded delivery mode of behavioral treatment for FSS populations [65]. Another research focus can be patient-environment interactions (ie, coping with issues at home, absenteeism, and return to work) as barriers and facilitators for demand within this target group.
For informing design and implementation of computer- and game-based modalities, it is useful to proceed with qualitative research and by formulating and testing theoretically informed hypotheses on how usage varies by patient, program design, behavioral, and context factors [26,61,66-68].

The degree of implementation of LAKA for eligible patients is not satisfactory, as could be expected when a CBI is offered under ad libitum conditions [69]. Besides blending with face-to-face delivery and multiplatform distribution, solutions for additional support can be provided through Web-based features such as tailored messages, prompts, and support via email, chat, or message boards [4]. Acceptability and limited efficacy outcomes should be treated with caution but suggest that LAKA is potentially efficacious and sufficiently engaging to complete once or twice (2-4 hours). Moderately positive enjoyment by users may reflect that the design principle of LAKA was not entirely hedonic, maybe at the expense of "playability" aspects [70]. Eliciting reflective and meditative states, LAKA was pleasant for a patient with concentration problems; however, self-reflections seem to be at the expense of a more satisfactory speed of interaction. Moreover, the game appears to provide opportunity to realize ideal selves, which supports intrinsic motivation [57]. However, LAKA also triggered serious reflections about discrepancy with "actual" selves, which is associated with somatic symptoms and negative emotions [71]. "Slowness" was mentioned as a reason for disengagement, but self-awareness was not. One may also reflect about how self-awareness in virtual reality relates to bodily and behavioral representations of Avatars [72] because extremely low perceived knowledge improvement levels were exclusively reported by patients with high BMI levels at baseline. High-quality and adequately powered studies on the effects of LAKA and similar systems on functional domains are needed to clarify the roles of self-conscious and affective states, learning, and degree of engagement $[16,17,73]$.

\section{Conclusion}

Although these first empirical findings support that an applied game is used by FSS patients for enjoyment and convenience, it became very clear that many patients would not be reached with a behavioral intervention of this modality under voluntary conditions. Social factors remain highly important for reaching many patients. LAKA will be feasible as a short and early intervention for patients, with adjustments of social and technical support. A next step in deployment and evaluation of the efficacy and cost-effectiveness of LAKA in a controlled study is recommendable.

\section{Acknowledgments}

Ciran, the developer of LAKA, sponsored the research described in this publication and contributed to the study design. Several partners made essential contributions to LAKA. We thank patients for their daily input. Lamas of Tibetan Institute, Yeunten Ling, Jan A.M. Jochijms, and Antonie E. Akkerman, are acknowledged for their contributions to the framing of the concept and operationalization of behavioral change content. Professor Dr. Jac L.A. Geurts guided the formulation of program requirements. Karel Michiels wrote scenarios. Finally, the creation and quality assurance of programming and art were outsourced to Paladin Studios. 


\section{Conflicts of Interest}

MV is employed by Ciran, and provided time and occasion to conduct independent doctoral research, by way of agreement, at Tranzo, Scientific Center for Care and Welfare. The terms of this arrangement have been reviewed and approved by Tranzo in accordance with its policy on objectivity in research. AB has been serving on the board of directors of Ciran. HV receives compensation for coordinating Ciran's scientific research agenda.

\section{Multimedia Appendix 1}

Conceptual framework.

[PDF File (Adobe PDF File), 394KB-Multimedia Appendix 1]

\section{Multimedia Appendix 2}

Serious gaming page.

[PDF File (Adobe PDF File), 654KB-Multimedia Appendix 2]

\section{Multimedia Appendix 3}

LAKA details.

[PDF File (Adobe PDF File), 1MB-Multimedia Appendix 3]

\section{Multimedia Appendix 4}

All measurement details.

[PDF File (Adobe PDF File), 771KB-Multimedia Appendix 4]

\section{Multimedia Appendix 5}

Regression models specified.

[PDF File (Adobe PDF File), 291KB-Multimedia Appendix 5]

\section{Multimedia Appendix 6}

Interview schedule.

[PDF File (Adobe PDF File), 440KB-Multimedia Appendix 6]

\section{Multimedia Appendix 7}

Method sensitivity analyses.

[PDF File (Adobe PDF File), 322KB-Multimedia Appendix 7]

\section{References}

1. Wantland DJ, Portillo CJ, Holzemer WL, Slaughter R, McGhee EM. The effectiveness of Web-based vs. non-Web-based interventions: A meta-analysis of behavioral change outcomes. J Med Internet Res 2004 Nov 10;6(4):e40 [FREE Full text] [doi: 10.2196/jmir.6.4.e40] [Medline: 15631964]

2. Eccleston C, Fisher E, Craig L, Duggan GB, Rosser BA, Keogh E. Psychological therapies (Internet-delivered) for the management of chronic pain in adults. Cochrane Database Syst Rev 2014;2:CD010152. [doi: 10.1002/14651858.CD010152.pub2] [Medline: 24574082]

3. Andersson G, Cuijpers P, Carlbring P, Riper H, Hedman E. Guided Internet-based vs. face-to-face cognitive behavior therapy for psychiatric and somatic disorders: A systematic review and meta-analysis. World Psychiatry 2014 Oct;13(3):288-295 [FREE Full text] [doi: 10.1002/wps.20151] [Medline: 25273302]

4. Murray E, Burns J, See TS, Lai R, Nazareth I. Interactive Health Communication Applications for people with chronic disease. Cochrane Database Syst Rev 2005(4):CD004274. [doi: 10.1002/14651858.CD004274.pub4] [Medline: 16235356]

5. Beatty L, Lambert S. A systematic review of internet-based self-help therapeutic interventions to improve distress and disease-control among adults with chronic health conditions. Clin Psychol Rev 2013 Jun;33(4):609-622. [doi: 10.1016/j.cpr.2013.03.004] [Medline: 23603521] 
6. Bleakley CM, Charles D, Porter-Armstrong A, McNeill MD, McDonough SM, McCormack B. Gaming for health: A systematic review of the physical and cognitive effects of interactive computer games in older adults. J Appl Gerontol 2015 Apr;34(3):NP166-NP189. [doi: 10.1177/0733464812470747] [Medline: 24652863]

7. Christensen H, Griffiths KM, Farrer L. Adherence in internet interventions for anxiety and depression. J Med Internet Res 2009;11(2):e13 [FREE Full text] [doi: 10.2196/jmir.1194] [Medline: 19403466]

8. Cuijpers P, van Straten A, Andersson G. Internet-administered cognitive behavior therapy for health problems: A systematic review. J Behav Med 2008 Apr;31(2):169-177 [FREE Full text] [doi: 10.1007/s10865-007-9144-1] [Medline: 18165893]

9. Geraghty AW, Wood AM, Hyland ME. Attrition from self-directed interventions: Investigating the relationship between psychological predictors, intervention content and dropout from a body dissatisfaction intervention. Soc Sci Med 2010 Jul;71(1):30-37. [doi: 10.1016/j.socscimed.2010.03.007] [Medline: 20400220]

10. Schubart JR, Stuckey HL, Ganeshamoorthy A, Sciamanna CN. Chronic health conditions and internet behavioral interventions: A review of factors to enhance user engagement. Comput Inform Nurs 2011 Feb;29(2):81-92. [doi: 10.1097/NCN.0b013e3182065eed] [Medline: 21164337]

11. Brouwer W, Kroeze W, Crutzen R, de Nooijer J, de Vries NK, Brug J, et al. Which intervention characteristics are related to more exposure to internet-delivered healthy lifestyle promotion interventions? A systematic review. J Med Internet Res 2011;13(1):e2 [FREE Full text] [doi: 10.2196/jmir.1639] [Medline: 21212045]

12. Rosser BA, Vowles KE, Keogh E, Eccleston C, Mountain GA. Technologically-assisted behaviour change: A systematic review of studies of novel technologies for the management of chronic illness. J Telemed Telecare 2009;15(7):327-338. [doi: 10.1258/jtt.2009.090116] [Medline: 19815901]

13. Baranowski T, Buday R, Thompson DI, Baranowski J. Playing for real: Video games and stories for health-related behavior change. Am J Prev Med 2008 Jan;34(1):74-82 [FREE Full text] [doi: 10.1016/j.amepre.2007.09.027] [Medline: 18083454]

14. Camerini L, Schulz PJ. Effects of functional interactivity on patients' knowledge, empowerment, and health outcomes: An experimental model-driven evaluation of a web-based intervention. J Med Internet Res 2012;14(4):e105 [FREE Full text] [doi: 10.2196/jmir.1953] [Medline: 22810046]

15. Morrison LG, Yardley L, Powell J, Michie S. What design features are used in effective e-health interventions? A review using techniques from Critical Interpretive Synthesis. Telemed J E Health 2012 Mar;18(2):137-144. [doi: 10.1089/tmj.2011.0062] [Medline: 22381060]

16. DeSmet A, Van Ryckeghem D, Compernolle S, Baranowski T, Thompson D, Crombez G, et al. A meta-analysis of serious digital games for healthy lifestyle promotion. Prev Med 2014 Dec;69:95-107. [doi: 10.1016/j.ypmed.2014.08.026] [Medline: 25172024]

17. Primack BA, Carroll MV, McNamara M, Klem ML, King B, Rich M, et al. Role of video games in improving health-related outcomes: A systematic review. Am J Prev Med 2012 Jun;42(6):630-638 [FREE Full text] [doi: 10.1016/j.amepre.2012.02.023] [Medline: 22608382]

18. Breivik H, Collett B, Ventafridda V, Cohen R, Gallacher D. Survey of chronic pain in Europe: Prevalence, impact on daily life, and treatment. Eur J Pain 2006 May;10(4):287-333. [doi: 10.1016/j.ejpain.2005.06.009] [Medline: 16095934]

19. Kroenke K. Patients presenting with somatic complaints: Epidemiology, psychiatric comorbidity and management. Int J Methods Psychiatr Res 2003;12(1):34-43. [Medline: 12830308]

20. Henningsen P, Zipfel S, Herzog W. Management of functional somatic syndromes. Lancet 2007 Mar 17;369(9565):946-955. [doi: 10.1016/S0140-6736(07)60159-7] [Medline: $\underline{\text { 17368156] }}$

21. Harvey SB, Wessely S. How should functional somatic syndromes be diagnosed? Int J Behav Med 2013 Jun;20(2):239-241. [doi: 10.1007/s12529-013-9300-7] [Medline: 23479340]

22. Bourke JH, Langford RM, White PD. The common link between functional somatic syndromes may be central sensitisation. J Psychosom Res 2015 Mar;78(3):228-236. [doi: 10.1016/j.jpsychores.2015.01.003] [Medline: 25598410]

23. Venkatesh $\mathrm{V}$, Thong $\mathrm{J}, \mathrm{Xu}$ X. Consumer acceptance and use of information technology: Extending the unified theory of acceptance and use of technology. MIS Quarterly 2012;36(1):157-178.

24. Venkatesh V, Thong JYL, Chan FKY, Hu PJ, Brown SA. Extending the two-stage information systems continuance model: Incorporating UTAUT predictors and the role of context. Information Systems Journal 2011;21(6):527-555.

25. Bowen DJ, Kreuter M, Spring B, Cofta-Woerpel L, Linnan L, Weiner D, et al. How we design feasibility studies. Am J Prev Med 2009 May;36(5):452-457 [FREE Full text] [doi: 10.1016/j.amepre.2009.02.002] [Medline: 19362699]

26. Kim J, Park HA. Development of a health information technology acceptance model using consumers' health behavior intention. J Med Internet Res 2012;14(5):e133 [FREE Full text] [doi: 10.2196/jmir.2143] [Medline: 23026508]

27. Or CK, Karsh BT. A systematic review of patient acceptance of consumer health information technology. J Am Med Inform Assoc 2009 Aug;16(4):550-560 [FREE Full text] [doi: 10.1197/jamia.M2888] [Medline: 19390112]

28. Ivankova NV, Creswell JW, Stick SL. Using mixed-methods sequential explanatory design: From theory to practice. Field Methods 2006 Feb 01;18(1):3-20. [doi: 10.1177/1525822X05282260]

29. Creswell DJW, Clark VLP. Designing and Conducting Mixed Methods Research. 2nd edition. USA: Sage Publications, Inc; 2007. 
30. Bossen D, Buskermolen M, Veenhof C, de Bakker D, Dekker J. Adherence to a web-based physical activity intervention for patients with knee and/or hip osteoarthritis: A mixed method study. J Med Internet Res 2013;15(10):e223 [FREE Full text] [doi: 10.2196/jmir.2742] [Medline: 24132044]

31. Garschagen A, Steegers MA, van Bergen AH, Jochijms JA, Skrabanja TL, Vrijhoef HJ, et al. Is there a need for including spiritual care in interdisciplinary rehabilitation of chronic pain patients? Investigating an innovative strategy. Pain Pract 2015 Sep 17;15(7):671-687. [doi: 10.1111/papr.12234] [Medline: 25229884]

32. Ryff CD, Singer B. Psychological well-being: Meaning, measurement, and implications for psychotherapy research. Psychother Psychosom 1996;65(1):14-23. [Medline: $\underline{8838692]}$

33. Magasi S, Post MW. A comparative review of contemporary participation measures' psychometric properties and content coverage. Arch Phys Med Rehabil 2010 Sep;91(9 Suppl):S17-S28. [doi: 10.1016/j.apmr.2010.07.011] [Medline: 20801275]

34. Abraham C, Michie S. A taxonomy of behavior change techniques used in interventions. Health Psychol 2008 May;27(3):379-387. [doi: 10.1037/0278-6133.27.3.379] [Medline: 18624603]

35. Lutz A, Dunne JD, Davidson RJ. Meditation and the neuroscience of consciousness: An introduction. In: Zelazo PD, Moscovitch M, Thompson E, editors. The Cambridge Handbook of Consciousness. Cambridge, UK: Cambridge University Press; 2007:497-549.

36. Jackson J. Stigma, liminality, and chronic pain: Mind-body borderlands. American Ethnologist 2005;32(3):332-353.

37. Venkatesh V, Morris M, Davis G, Davis F. User acceptance of information technology: Toward a unified view. MIS quarterly 2003:425-478.

38. Turner H, Bryant-Waugh R, Peveler R, Bucks RS. A psychometric evaluation of an English version of the Utrecht Coping List. Eur Eat Disord Rev 2012 Jul;20(4):339-342. [doi: 10.1002/erv.2173] [Medline: 22419565]

39. Nunnally J, Bernstein IH. Psychometric methods. In: Psychometric Theory. New York: McGraw-Hill; 1994.

40. Or CK, Karsh B, Severtson DJ, Burke LJ, Brown RL, Brennan PF. Factors affecting home care patients' acceptance of a web-based interactive self-management technology. J Am Med Inform Assoc 2011 Feb;18(1):51-59 [FREE Full text] [doi: 10.1136/jamia.2010.007336] [Medline: 21131605]

41. Van der Heijden H. User acceptance of hedonic information systems. MIS Quarterly 2004:695-704.

42. Vallejo MA, Jordán CM, Díaz MI, Comeche MI, Ortega J. Psychological assessment via the internet: A reliability and validity study of online (vs paper-and-pencil) versions of the General Health Questionnaire-28 (GHQ-28) and the Symptoms Check-List-90-Revised (SCL-90-R). J Med Internet Res 2007;9(1):e2 [FREE Full text] [doi: 10.2196/jmir.9.1.e2] [Medline: $\underline{17478411]}$

43. Brenninkmeijer V, VanYperen N. How to conduct research on burnout: Advantages and disadvantages of a unidimensional approach in burnout research. Occup Environ Med 2003 Jun;60 Suppl 1:i16-i20 [FREE Full text] [Medline: 12782742]

44. Fu FL, Su RC, Yu SC. EGameFlow: A scale to measure learners' enjoyment of e-learning games. Computers \& Education 2009;52(1):101-112.

45. Oshlyansky L, Cairns P, Thimbleby H. Validating the Unified Theory of Acceptance and Use of Technology (UTAUT) tool cross-culturally. In: Proceedings of the 21st British HCI Group Annual Conference on People and Computers: HCI but not as we know it. 2007 Presented at: 21st British HCI Group Annual Conference on People and Computers; September 3-7; Lancaster, United Kingdom.

46. Davis FD, Venkatesh V. A critical assessment of potential measurement biases in the technology acceptance model: Three experiments. International Journal of Human-Computer Studies 1996;45(1):19-45.

47. Price DD, Bush FM, Long S, Harkins SW. A comparison of pain measurement characteristics of mechanical visual analogue and simple numerical rating scales. Pain 1994 Feb;56(2):217-226. [Medline: $\underline{8008411]}$

48. Dittner AJ, Wessely SC, Brown RG. The assessment of fatigue: A practical guide for clinicians and researchers. J Psychosom Res 2004 Feb;56(2):157-170. [doi: 10.1016/S0022-3999(03)00371-4] [Medline: 15016573]

49. Arindell WA, Ettema JHM. SCL-90, Handleiding bij een Multidimensionele Psychopathologie-Indicator. Amsterdam, Netherlands: Swets \& Zeitlinger B.V; 1986.

50. Stomp-van der Berg S, Vlaeyen J, Ter KM, Spinhoven P, van BG, Kole-Snijders A. Meetinstrumenten chronische pijn deel 2 Pijn Coping en Cognitie Lijst (PCCL). Maastricht: Pijn Kennis Centrum Academisch Ziekenhuis Maastricht 2001.

51. Roelofs J, Goubert L, Peters ML, Vlaeyen JW, Crombez G. The Tampa Scale for Kinesiophobia: further examination of psychometric properties in patients with chronic low back pain and fibromyalgia. Eur J Pain 2004 Oct;8(5):495-502. [doi: 10.1016/j.ejpain.2003.11.016] [Medline: 15324781]

52. Baron RM, Kenny DA. The moderator-mediator variable distinction in social psychological research: Conceptual, strategic, and statistical considerations. J Pers Soc Psychol 1986 Dec;51(6):1173-1182. [Medline: 3806354]

53. VERBI GmbH. 1995. MAXQDA 11 URL: http://www.maxqda.com/products/maxqda11 [accessed 2015-04-16] [WebCite Cache ID 6XpOq7xmD]

54. Morley S, Williams A, Hussain S. Estimating the clinical effectiveness of cognitive behavioural therapy in the clinic: Evaluation of a CBT informed pain management programme. Pain 2008 Jul 31;137(3):670-680. [doi:

10.1016/j.pain.2008.02.025] [Medline: 18394806 ] 
55. Prins JB, Bleijenberg G, Bazelmans E, Elving LD, de Boo TM, Severens JL, et al. Cognitive behaviour therapy for chronic fatigue syndrome: A multicentre randomised controlled trial. Lancet 2001 Mar 17;357(9259):841-847. [doi: 10.1016/S0140-6736(00)04198-2] [Medline: 11265953]

56. UNESCO. 1997. International Standard Classification of Education URL: http://www.unesco.org/education/information/ nfsunesco/doc/isced 1997.htm[WebCite Cache ID 6VcqPwizW]

57. Vercoulen JH, Hommes OR, Swanink CM, Jongen PJ, Fennis JF, Galama JM, et al. The measurement of fatigue in patients with multiple sclerosis. A multidimensional comparison with patients with chronic fatigue syndrome and healthy subjects. Arch Neurol 1996 Jul;53(7):642-649. [Medline: 8929171]

58. Donkin L, Hickie IB, Christensen H, Naismith SL, Neal B, Cockayne NL, et al. Sampling bias in an internet treatment trial for depression. Transl Psychiatry 2012;2:e174 [FREE Full text] [doi: 10.1038/tp.2012.100] [Medline: 23092978]

59. Geladi P, Kowalski BR. Partial least-squares regression: A tutorial. Analytica Chimica Acta 1986;185:1-17. [doi: $10.1016 / 0003-2670(86) 80028-9]$

60. Hayes AF. Beyond Baron and Kenny: Statistical mediation analysis in the new millennium. Communication Monographs 2009 Dec;76(4):408-420. [doi: 10.1080/03637750903310360]

61. Szalma JL. On the application of motivation theory to human factors/ergonomics: Motivational design principles for human-technology interaction. Hum Factors 2014 Dec;56(8):1453-1471. [Medline: 25509824]

62. Przybylski AK, Weinstein N, Murayama K, Lynch MF, Ryan RM. The ideal self at play: The appeal of video games that let you be all you can be. Psychol Sci 2012 Jan 1;23(1):69-76. [doi: 10.1177/0956797611418676] [Medline: 22173739]

63. Nes L, Roach A, Segerstrom S. Executive functions, self-regulation, and chronic pain: A review. Annals of Behavioral Medicine 2009;37(2):173-183.

64. Arrindell WA, Barelds DP, Janssen I, Buwalda FM, van der Ende J. Invariance of SCL-90-R dimensions of symptom distress in patients with peri partum pelvic pain (PPPP) syndrome. Br J Clin Psychol $2006 \mathrm{Sep}$;45(Pt 3):377-391. [Medline: $\underline{17147103}$ ]

65. Ritterband LM, Cox DJ, Gordon TL, Borowitz SM, Kovatchev BP, Walker LS, et al. Examining the added value of audio, graphics, and interactivity in an Internet intervention for pediatric encopresis. Children's Health Care 2006;35(1):47-59.

66. Ahadzadeh AS, Pahlevan SS, Ong FS, Khong KW. Integrating health belief model and technology acceptance model: An investigation of health-related internet use. J Med Internet Res 2015;17(2):e45 [FREE Full text] [doi: 10.2196/jmir.3564] [Medline: 25700481]

67. Beaudry A, Pinsonneault A. The other side of acceptance: Studying the direct and indirect effects of emotions on information technology use. MIS Quarterly 2010;34(4):689-710.

68. Kelders SM, Kok RN, Ossebaard HC, Van Gemert-Pijnen JE. Persuasive system design does matter: A systematic review of adherence to web-based interventions. J Med Internet Res 2012;14(6):e152 [FREE Full text] [doi: 10.2196/jmir.2104] [Medline: 23151820]

69. Botella C, Garcia-Palacios A, Vizcaíno Y, Herrero R, Baños RM, Belmonte MA. Virtual reality in the treatment of fibromyalgia: A pilot study. Cyberpsychol Behav Soc Netw 2013 Mar;16(3):215-223. [doi: 10.1089/cyber.2012.1572] [Medline: 23496678]

70. Sánchez JLG, Vela FLG, Simarro FM, Padilla-Zea N. Playability: Analysing user experience in video games. Behaviour \& Information Technology 2012 Mar;31(10):1033-1054. [doi: 10.1016/j.jpainsymman.2003.07.001]

71. Waters SJ, Keefe FJ, Strauman TJ. Self-discrepancy in chronic low back pain: Relation to pain, depression, and psychological distress. J Pain Symptom Manage 2004 Mar;27(3):251-259. [doi: 10.1016/j.jpainsymman.2003.07.001] [Medline: 15010103]

72. Kim Y, Sundar SS. Visualizing ideal self vs actual self through avatars: Impact on preventive health outcomes. Computers in Human Behavior 2012;28(4):1356-1364.

73. Glegg SM, Tatla SK, Holsti L. The GestureTek virtual reality system in rehabilitation: A scoping review. Disabil Rehabil Assist Technol 2014 Mar;9(2):89-111. [doi: 10.3109/17483107.2013.799236] [Medline: 23713408]

\section{Abbreviations}

BI: behavioral intention

CBI: computer-based interventions

FSS: functional somatic syndromes

IRP: interdisciplinary rehabilitation program

QL: qualitative

QN: quantitative 
Edited by G Eysenbach; submitted 29.08.15; peer-reviewed by D Bossen, FS Ong, P Schulz, WC Su; comments to author 04.11.15; revised version received 24.12.15; accepted 19.01.16; published 01.04.16

Please cite as:

Vugts MAP, Joosen MCW, van Bergen AHMM, Vrijhoef HJM

Feasibility of Applied Gaming During Interdisciplinary Rehabilitation for Patients With Complex Chronic Pain and Fatigue Complaints:

A Mixed-Methods Study

JMIR Serious Games 2016;4(1):e2

URL: http://games.jmir.org/2016/1/e2/

doi: $10.2196 /$ games.5088

PMID: 27036094

CMiel A P Vugts, Margot C W Joosen, Alfonsus H M M van Bergen, Hubertus J M Vrijhoef. Originally published in JMIR Serious Games (http://games.jmir.org), 01.04.2016. This is an open-access article distributed under the terms of the Creative Commons Attribution License (http://creativecommons.org/licenses/by/2.0/), which permits unrestricted use, distribution, and reproduction in any medium, provided the original work, first published in JMIR Serious Games, is properly cited. The complete bibliographic information, a link to the original publication on http://games.jmir.org, as well as this copyright and license information must be included. 